\title{
Winter 2015/16 Atmospheric and Precipitation Anomalies over North America: EI Niño Response and the Role of Noise ${ }^{\mathscr{O}}$
}

\author{
Mingyue CHEN AND ARUn KumAR \\ Climate Prediction Center, NOAA/NWS/NCEP, College Park, Maryland
}

(Manuscript received 28 April 2017, in final form 5 February 2018)

\begin{abstract}
The possible causes for the observed winter 2015/16 precipitation anomalies, which were opposite to the mean El Niño signal over the U.S. Southwest, are analyzed based on the ensemble of forecasts from the NCEP Climate Forecast System, version 2 (CFSv2). The analysis focuses on the role of anomalous sea surface temperature (SST) forcing and the contributions of atmospheric internal variability. The model-predicted ensemble mean forecast for December-January-February 2015/16 (DJF 2015/16) North American atmospheric anomalies compared favorably with the El Niño composite, although some difference existed. The predicted pattern was also like that in the previous strong El Niño events of 1982/83 and 1997/98. Therefore, the model largely predicted the teleconnection and precipitation response pattern in DJF 2015/16 like the mean El Niño signal. The observed negative precipitation anomalies over the U.S. Southwest in DJF 2015/16 were not consistent either with the observed or with the model-predicted El Niño composite. Analysis of the member-to-member variability in the ensemble of forecast anomalies allowed quantification of the contribution of atmospheric internal variability in shaping seasonal mean anomalies. There were considerable variations in the outcome of DJF 2015/16 precipitation over North America from one forecast to another even though the predicted SSTs were nearly identical. The observed DJF 2015/16 precipitation anomalies were well within the envelope of possible forecast outcomes. Therefore, the atmospheric internal variability could have played a considerable role in determining the observed DJF 2015/16 negative precipitation anomalies over the U.S. Southwest, and its role is discussed in the context of differences in response.
\end{abstract}

\section{Introduction}

In forecasting seasonal mean atmospheric variability, a major contribution to predictive skill is from slowly varying boundary conditions. Previous studies based on observations and numerical model simulations have shown that the atmospheric response to the anomalous tropical sea surface temperature (SST) associated with El Niño-Southern Oscillation (ENSO) is the dominant predictable component in the seasonal climate variability (Shukla and Wallace 1983; Kumar and Hoerling 1995; Barnston and Smith 1996; Lau 1997; Trenberth et al. 1998; Kumar and Hoerling 1998; DelSole and Shukla 2006; National Research Council

\footnotetext{
Supplemental information related to this paper is available at the Journals Online website: https://doi.org/10.1175/MWR-D-170116.s1.
}

\footnotetext{
Corresponding author: Dr. Mingyue Chen, mingyue.chen@noaa gov
}

2010). For the climate variability over North America (NA), the mean signal of winter precipitation response to the anomalous warm ENSO SSTs includes belownormal conditions over the northern United States and above-normal conditions across the southern part of the United States (Ropelewski and Halpert 1986, 1987, 1989; Livezey et al. 1997; Trenberth et al. 1998). During the strong El Niño event of 2015/16 winter, however, the observed precipitation anomalies over the U.S. West Coast differed in their spatial pattern from that of the canonical signal during El Niño conditions. As shown in Fig. 1c, the observed 3-month seasonal mean of precipitation anomalies from December 2015 to February 2016 was positive over the Pacific Northwest and negative over the U.S. Southwest and Mexico. The observed precipitation anomalies, therefore, were opposite in sign to the mean El Niño signal based on a composite of the observed historical El Niño events (Fig. 1d). The observed seasonal mean precipitation anomalies were also not favored by the official NOAA seasonal outlooks. The observed 

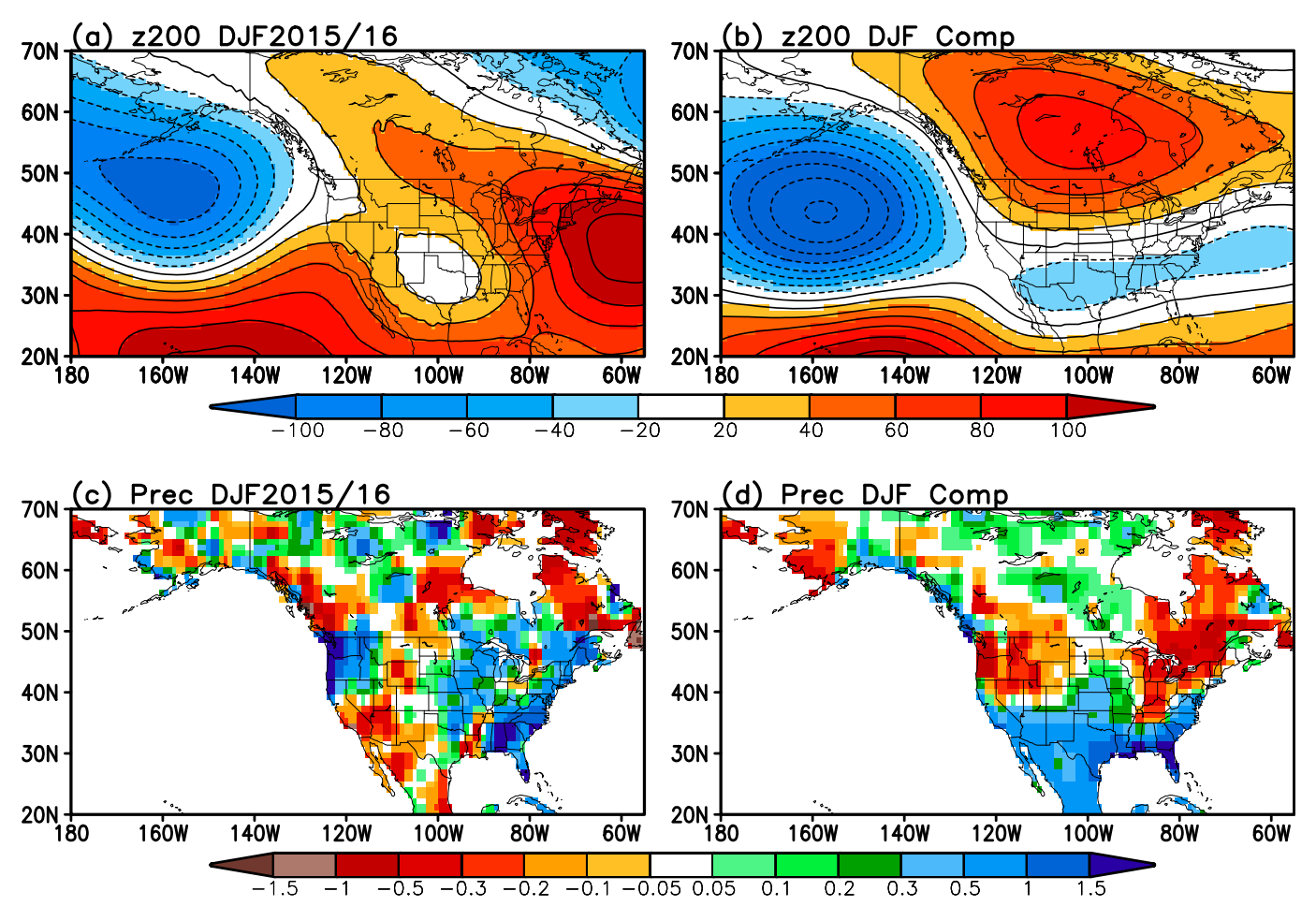

FIG. 1. (a),(c) The observed anomalies of 200-mb height (m) over the PNA region and precipitation $\left(\mathrm{mm} \mathrm{day}^{-1}\right)$ over North America in DJF 2015/16 and (b),(d) their corresponding El Niño composites. The amplitude of anomalies in the composite are adjusted to match that in DJF 2015/16 based on the Niño-3.4 index.

precipitation anomaly was also opposite to the ensemble mean forecast anomaly (which is likely to be dominated by the response to SSTs) from many dynamical seasonal forecast systems, for example, the North American Multimodel Ensemble (NMME; Kirtman et al. 2014).

One possible reason that the observed 2015/16 winter seasonal precipitation anomalies differed from the mean El Niño signal is the SST differences in 2015/ 16 from a typical El Niño SST condition in the historical period. Such differences in SSTs may also lead to sensitivity in the atmospheric responses. Differences in SSTs could be due to the 2015/16 event belonging to a different flavor of El Niño SSTs or because of the observed warming of SSTs in the Indian or North Pacific Ocean. However, previous studies have found that the variability in the spatial pattern of extratropical atmospheric response to different tropical SST forcing, although present, is not appreciable enough beyond the canonical response (Kumar and Hoerling 1997; Barsugli and Sardeshmukh 2002; Hoerling and Kumar 2002; Peng and Kumar 2005) that it can change the response during DJF 2015/16 to the observed precipitation pattern. Further, the strong SST anomalies in the North Pacific Ocean themselves may have been forced by the atmospheric circulations (Bond et al. 2015; Hartmann 2015; Seager et al. 2015; Hu et al. 2017). The response of the atmosphere to extratropical SST anomalies, as yet, remains a controversial issue and cannot be offered as a causal explanation with confidence (Robinson 2000; Kumar and Wang 2015). Nonetheless, the uniqueness of the anomalous SST pattern during 2015/16 may still have influenced the atmospheric response to differ from the El Niño composite leading to changes the probability of seasonal mean outcomes, and thereby, may have altered the likelihood of the observed outcome. The observed atmospheric anomalies could also have been influenced by anomalies in other boundary conditions including the extended dry conditions over the western United States (Seager et al. 2015).

The second class of possible explanations belongs to the category that the atmospheric response pattern to El Niño itself may be changing because of trends in SSTs or some other external forcing like $\mathrm{CO}_{2}$, sea ice, etc. It is also unlikely to be the case (Quan et al. 2018). Many attribution analyses about the extreme climate events, for example, the 2011 Texas drought/heat wave (Hoerling et al. 2013), the March 2012 central and eastern U.S. extreme warm event (Dole et al. 2014), and the 2011-14 California drought (Seager et al. 2015), 
have shown that the changes in climate variability caused by increasing greenhouse gases are small compared to the amplitude of anomalies during extreme events. Therefore, it is unlikely that the influence from the subtle, and gradual, changes in anthropogenic forcings could result in a complete reversal of the atmospheric response pattern over the U.S. Southwest from positive precipitation anomalies in the historical period to negative anomalies in 2015/16 winter.

While a class of reasons why the observed precipitation over the U.S. Southwest differed from the El Niño response relies on sensitivity in the atmospheric response to factors beyond the canonical El Niño response, another possibility is the role the atmospheric internal variability can play on the outcomes of individual seasonal means (Kumar et al. 2013). It is well known that the unpredictable atmospheric internal variability is a large component of the total variability in the extratropical latitudes (Madden 1976; Horel and Wallace 1981; Kumar and Hoerling 1995; Kumar et al. 2007; Jha et al. 2018). The role of atmospheric internal variability can also be readily established from AGCM simulations with the repeating annual cycle of external forcings and analyzing differences in outcomes for a particular season over different years. The need to sample the contribution of atmospheric internal variability is also implicit in the design of ensemble forecasting approach (Kumar and Chen 2015).

The observed anomaly for an individual season is a sum of response to external forcings and random noise associated with the internal variability. Given the large amplitude of atmospheric internal variability, another hypothesis could be that the observed 2015/16 winter precipitation anomalies over the U.S. Southwest differed from the mean El Niño composite because of a substantial contribution of atmospheric internal variability (noise) superimposed on the atmospheric response (signal) to El Niño SSTs. In fact, because of the large amplitude of atmospheric internal variability, one can even argue this to be the null hypothesis. Exploring the influence of differences in the response to SSTs in 2015/16, and contribution of atmospheric internal variability in shaping seasonal mean outcomes is the focus of our analysis. To overcome the limitations of sampling issue in observational data, the analysis is based on an ensemble of retrospective forecasts (hindcasts) and realtime forecasts from the National Centers for Environmental Prediction (NCEP) current operational Climate Forecast System, version 2 (CFSv2).

For understanding climate variability and analyzing the causes why the forecasts may have differed from the observations, the analysis of seasonal forecasts from CFSv2 has some positive attributes: 1) the forecasts are based on a coupled system, and therefore, one of the potential shortcoming of using ensemble AMIP simulations approach in representing coupled air-sea interaction is ameliorated; 2) large forecast ensembles are routinely generated as part of operational requirements and allows one to study the responses to external forcings and then quantify the possible range of outcomes of seasonal anomalies due to the internal variability without involving extra computational overhead; 3) initialization of the state of ocean conditions is close to the target forecast time, consequently SST forecast errors are small and the influence of errors in SST forcing on atmospheric response is also likely to be small; 4) the observed increases in $\mathrm{CO}_{2}$ and its influence is included in the forecast system; and 5) the inclusion of the atmospheric and land initial conditions from the realistic data assimilation system allows one to quantify the role of these initial conditions on seasonal means. Given these attributes, the use of ensemble forecasts from the initialized seasonal forecast systems has been documented in many studies (e.g., Peng and Kumar 2005, Kumar et al. 2013; Chen and Kumar 2015; Weisheimer et al. 2017). Following a similar approach, in this study we analyze the atmospheric response to SSTs based on the ensemble mean of forecast members from CFSv2 and assess the contribution of atmospheric noise based on the spread among individual forecasts members. A disadvantage of using coupled seasonal forecasts for analyzing the causes why the forecasts may have differed from the observations is that the individual contribution from different possible sources in determining atmospheric response is harder to quantify. The latter analysis is much more amenable following the AMIP simulation paradigm where the evolution of external forcings can be controlled, for example, the analysis methodology used by Siler et al. (2017) and Paek et al. (2017).

\section{Datasets and analysis approaches}

In the present analysis we use ensemble forecast data from the NCEP CFSv2. CFSv2 is a fully coupled general circulation model and provides 9-month forecasts. The initial conditions of ocean-atmosphere-land are from the Climate Forecast System Reanalysis (CFSR; Saha et al. 2010). In the CFSv2 forecasts, the observed greenhouse gas $\mathrm{CO}_{2}$ concentration is specified, and hence, its increasing trends since 1982 are included. CFSv2 shows forecast skills comparable with other climate forecast models for seasonal anomalies of SST and atmospheric and terrestrial variables such as precipitation and temperature (Xue et al. 2013; Saha et al. 2014; Becker and van den Dool 2016). 
CFSv2 also provides forecasts of large ensemble size. For the hindcasts, for each of 30 years during 1982-2011, there are 4 forecast members initialized at 0000, 0600, 1200 , and 1800 UTC every fifth day starting from 1 January. For the real-time forecasts, there are 4 forecast members initialized at 0000, 0600, 1200, and 1800 every day. In the analysis, we subsample the real-time forecasts to every fifth day initial conditions in each year of 2012-14 to mimic the hindcast configuration.

We first analyzed the atmospheric response to forecast SSTs based on the ensemble mean of forecasts. This analysis focused on how well the 2015/16 winter NA atmospheric and precipitation anomalies were predicted as an ensemble mean atmospheric response, and how the pattern of 2015/16 winter anomalies in the forecast ensemble mean compared to that of the El Niño composite. Although the ensemble mean in the initialized climate forecast system could also have contributions from the responses to external forcings other than SSTs, for example, soil moisture, changes in the $\mathrm{CO}_{2}$, and influences of the atmospheric initial conditions, contributions of these factors in the context of our analysis is likely to be small. This is because the changes of the $\mathrm{CO}_{2}$ in 2015/16 relative to its 1982-2010 climatology is small, the time scale associated with atmospheric initial conditions is short (Chen et al. 2010; Peng et al. 2011), and the decay of soil moisture influence is also short (Wang and Kumar 1998; Guo et al. 2011). We will revisit this discussion when the differences in the CFSv2 El Niño response in 2015/16 and the El Niño composite are compared with the observed seasonal mean anomalies in 2015/16. We also assessed the contribution of atmospheric noise based on individual forecast members to examine how much anomalies in the individual forecasts can differ from the ensemble means, and if the observed 2015/16 winter atmospheric anomalies were within the envelope of variability in the ensemble of forecasts.

To minimize the influence of errors in forecast SST forcing in the model forecasts, we use the ensemble forecasts from the initial conditions with the shortest lead time. The ensemble forecasts for 2015/16 winter are 40 members of December-January-February (DJF) seasonal mean forecasts initialized on the last 10 days in November 2015, and for the historical period are 20 members of DJF forecasts initialized on 7, 12, 17, 22, and 27 November from 1982 to 2014.

For a clear comparison of atmospheric response in DJF 2015/16 to that in the historical period, the composite includes El Niño events only in 1982-2014. The years with the observed CPC oceanic Niño index anomaly above 0.5 of its standard deviation are defined as El Niño resulting in $11 \mathrm{El}$ Niño events in 1982-2014 (the DJFs of 1982/83, 1986/87,
1987/88, 1991/92, 1994/95, 1997/98, 2002/03, 2004/05, 2006/ 07, 2009/10, and 2014/15).

The variables analyzed in this study include SST, precipitation, and $200-\mathrm{mb}(1 \mathrm{mb}=1 \mathrm{hPa})$ height. The corresponding observed seasonal mean quantities are the following: SST from the National Centers for Environmental Information (NCEI) daily high-resolution SST analysis (Reynolds et al. 2007), precipitation from the Climate Anomaly Monitoring System-Outgoing longwave radiation Precipitation Index (CAMS-OPI) (Janowiak and Xie 1999), and 200-mb height from the CFSR (Saha et al. 2010).

To reduce the biases in CFSv2 tropical SST forecasts caused by the discontinuity around 1999 in initial conditions taken from CFSR (Kumar et al. 2012), following the method in Kumar and Chen (2017) and other previous studies, we use two-period climatology to compute the seasonal mean anomalies for both model forecasts and observations. Consequently, the 1982-98 (19992015) seasonal anomalies are relative to the 1982-98 (1999-2010) climatology. The seasonal anomalies in DJF 2015/16 are based on the climatology of 1999-2010. By constructing the anomalies with this two-period climatology, the influence of long-term trend since 1982 is also reduced.

\section{Results}

\section{a. The observed anomalies in DJF 2015/16 and the El Niño composite}

The observed anomalies of precipitation and 200-mb height in DJF 2015/16, together with the El Niño composites from $11 \mathrm{El}$ Niño events in 1982-2014 over the Pacific-North American (PNA) domain are shown in Fig. 1. We note that all the composites are scaled by a factor (2.06) such that Niño-3.4 anomalies in the composite are the same as that for DJF 2015/16.

For the 200-mb height, the spatial pattern correlation between the observed anomalies in DJF 2015/16 and the El Niño composite is 0.62 (Table 1), and differences in the locations of positive and negative anomalies and the centers of maximum anomalies are noticeable. In the El Niño composite, the North Pacific (NP) negative height anomalies extend from its center in the northeast Pacific to the southern United States and the subtropical Pacific jet shifted toward the southern part of the U.S. West Coast. In DJF 2015/16, the tropical positive height anomalies extended farther into the northern subtropical Pacific and the U.S. Southwest and the NP negative height anomalies were confined to the northeast Pacific only. Consequently, the subtropical Pacific jet was tilted toward the northern part of the U.S. West Coast. 
TABLE 1. Spatial anomaly correlations of the observed DJF 2015/16 anomalies with the observed El Niño composite of DJFs in 1982-2014 for SSTs, precipitation (Prec), and 200-mb height (z200) over the tropics $\left(30^{\circ} \mathrm{S}-30^{\circ} \mathrm{N}\right), \mathrm{z} 200$ over the region of Pacific-North America (PNA, $20^{\circ}-70^{\circ} \mathrm{N}, 180^{\circ}-60^{\circ} \mathrm{W}$ ), and Prec over North America $\left(\mathrm{NA} ; 20^{\circ}-70^{\circ} \mathrm{N}\right)$.

\begin{tabular}{lc}
\hline \multicolumn{1}{c}{ Variable } & Observed $2015 / 16$-observed composite \\
\hline SST (tropics) & 0.87 \\
Prec (tropics) & 0.85 \\
z200 (tropics) & 0.93 \\
z200 (PNA) & 0.62 \\
Prec (NA) & 0.06 \\
\hline
\end{tabular}

Corresponding to the direction and location of the Pacific jet that directs the storms from the Pacific, and the spatial pattern and position of the height anomalies that indicates the cyclonic (anticyclonic) circulation over Oregon and Washington (Southern California), the DJF 2015/16 precipitation showed large positive anomalies in the Pacific Northwest and negative anomalies in the U.S. Southwest. For the El Niño composite, on the other hand, the positive precipitation anomalies are over the southern part of the United States, which are opposite in sign of precipitation anomaly in DJF 2015/16.

Figure 2 illustrates the observed anomalies of SST, precipitation, 200-mb height, and 200-mb divergence in DJF 2015/16 (the left panels) and the El Niño composite (the right panels) from the tropics to the northern extratropics. In the eastern equatorial Pacific, the observed SST seasonal anomalies reached above $3 \mathrm{~K}$ making this El Niño event comparable with the strongest El Niño events of 1982/83 and 1997/98 during the past 60 years. The precipitation anomalies in DJF 2015/16 had a large positive anomaly over the region across the central to eastern equatorial Pacific and a negative anomaly over the region extended from the western Pacific, Maritime Continent, and northern Australia to north- and southeast subtropical Pacific. The observed precipitation in the tropical latitudes was much more canonical and resembled well the El Niño composite. The 200-mb height had a strong anomalous positive value over the central to eastern tropical Pacific, and once again resembled well the El Niño composite. As expected, both the 200-mb divergence in DJF 2015/16 and the composite show the large divergence over the equatorial central Pacific where the precipitation also has large positive anomalies. The likeness between anomalies in DJF 2015/16 and the El Niño composite in tropical latitudes is confirmed by high correlations of their spatial patterns, which are $0.87,0.85$, and 0.93 for the SST, precipitation, and 200-mb height, respectively, over $30^{\circ} \mathrm{S}-30^{\circ} \mathrm{N}$ (Table 1 ).
In summary, the observed 2015/16 winter tropical forcing for global circulation agreed fairly well with the historical response during El Niño events. This contrasts with the observed anomalies over the PNA region in Fig. 1 where observed anomalies had differences from the El Niño composite. This indicates that even though the tropical forcing for the tropical-extratropical teleconnection during the 2015/16 ENSO event was similar to the composite, the observed extratropical anomalies still differed from the expected El Niño response. These differences could either be due to the contribution of atmospheric internal variability to the observed seasonal mean anomalies or could reflect changes in the response to external factors that were unique to the 2015/16 El Niño event. To understand the contribution from different factors, we next analyzed possible reasons why the NA atmospheric anomalies in DJF 2015/16 may have differed from the composite El Niño signal based on the ensemble of forecasts from CFSv2.

\section{b. Atmospheric response to SSTs in model forecasts}

Although the observed SST and precipitation during DJF 2015/16 had a good correspondence with their respective composites over the tropics, there are subtle differences. The differences include larger SST warming over the Indian Ocean that is also accompanied by differences in precipitation anomalies. It is conceivable that such differences from the El Niño composite response in tropics matter in determining tropicalextratropical interactions. Following this argument, the observed DJF 2015/16 anomalies over NA conformed to an altered El Niño response. Similarly, because of prolonged drought over California leading to DJF 2015/16 (Seager et al. 2015), there were appreciable soil moisture anomalies that might have also influenced the seasonal mean response to El Niño. The consequences of these possibilities cannot be validated based on observational analysis alone because it requires an estimate of response that is specific to the SSTs and other boundary conditions observed in DJF 2015/16, but could be addressed based on the analysis of model ensemble forecasts.

The atmospheric response to SSTs in 2015/16 winter is analyzed using the ensemble means of CFSv2 forecasts. We examine 1) how well the $2015 / 16$ winter tropical forcing for global circulation was forecasted; 2) how well the 2015/16 winter NA atmospheric anomalies were forecasted as an ensemble mean atmospheric response; and 3) if the pattern of 2015/16 winter NA ensemble mean response was similar to that of the historical El Niño composite, and if not then whether the differences from the composite were adequate to explain differences in the observed precipitation from the expected El Niño response. 

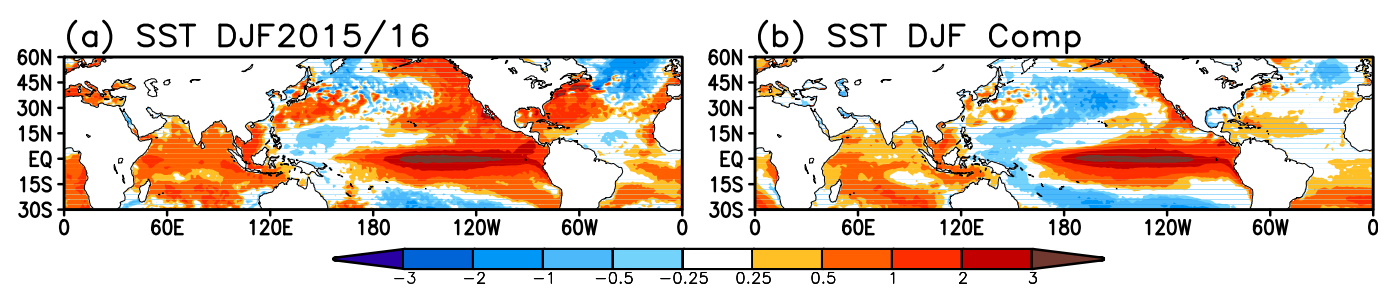

(c) Prec DJF2015/16

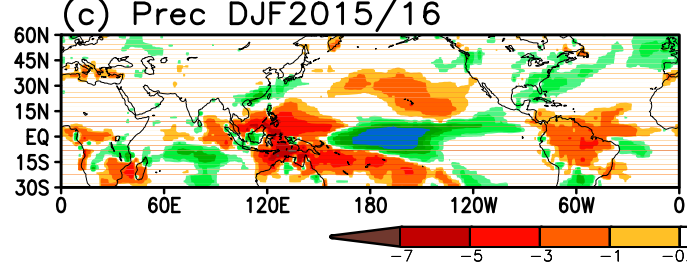

(e) z200 DJF $2015 / 16$

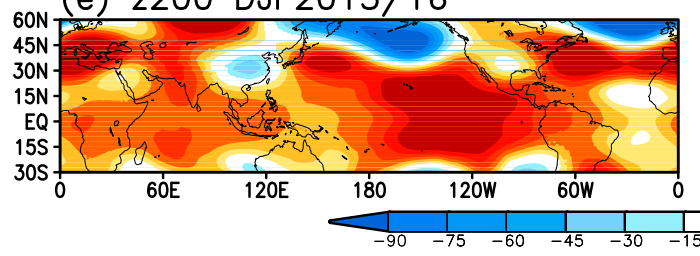

(g) $200 \mathrm{mb}$ Div DJF2015/16

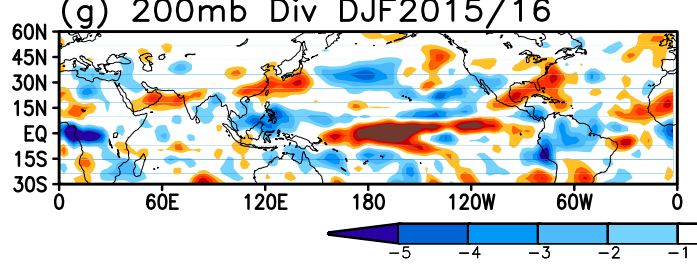

FIG. 2. (a),(c),(e),(g) Observed anomalies of SST (K), precipitation $\left(\mathrm{mm} \mathrm{day}^{-1}\right), 200-\mathrm{mb}$ height (m), and $200-\mathrm{mb}$ divergence $\left(1.0 \times 10^{-6} \mathrm{~s}^{-1}\right)$ over the global region from $30^{\circ} \mathrm{S}$ to $60^{\circ} \mathrm{N}$ in DJF $2015 / 16$, and (b), (d), (f), (h) their corresponding observed El Niño composites. The amplitudes of anomalies in the composite are adjusted to match that in DJF 2015/16 based on the Niño-3.4 SST index.
Figure 3 (left panels) shows CFSv2 ensemble mean forecasts of SST, precipitation, and 200-mb height over the tropics and northern extratropics for DJF 2015/16 from 40 members initialized in the last 10 days of the November 2015. For the short lead forecast, the SST seasonal means are well predicted, except for over the equatorial Atlantic Ocean. The strong warm SST anomalies over the central-eastern tropical Pacific and warm anomalies over Indian Ocean and the northeast Pacific in the prediction were very close to their observational counterpart. The predicted ensemble means of DJF 2015/16 precipitation anomalies, which represent the atmospheric response to SSTs, captured well the major features in observations; predictions had large positive anomalies over the central-eastern equatorial Pacific that were surrounded by negative anomalies to north, west, and southwest. The 200-mb height response had large-amplitude positive anomalies over the centraleastern Pacific and matched well with observations (cf. Figs. 2e and 3e). The ensemble means for DJF 2015/16 (d) Prec DJF Comp

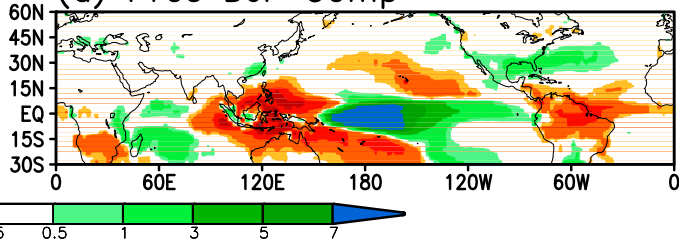

(f) z200 DJF Comp

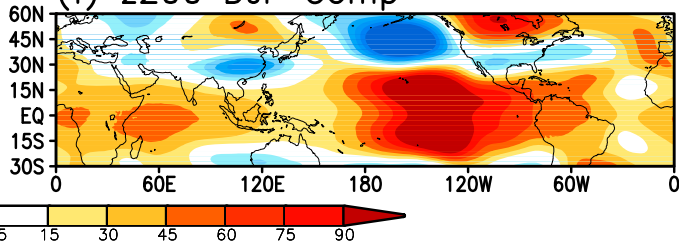

(h) $200 \mathrm{mb}$ Div DJF Comp

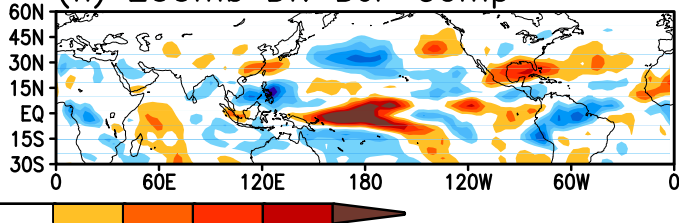

SST, precipitation, and 200-mb height over the tropics have good correlation with the observations (Table 2). This analysis confirms that the tropical forcings for global circulation are well forecasted for DJF 2015/16 and the observed anomalies in the atmosphere in the tropics can be attributed to the observed SSTs associated with El Niño.

To assess if the tropical atmospheric response to the observed SST forcings in DJF 2015/16 changed from El Niño in the historical period, an appropriately scaled composite of $11 \mathrm{El}$ Niño events from model forecasts for DJF in 1982-2014 are shown in Fig. 3 (right panels). The spatial pattern correlations between the DJF 2015/16 anomalies and their corresponding El Niño composite are listed in Table 2. The comparison shows that tropical atmospheric response to SST forcings in DJF 2015/16 is similar to that in the historical El Niño composite. We note that for the tropics, the spatial correlation of observed and model anomalies with the corresponding composites is about the same (Tables 1 and 2) even 
(a) SST DJF2015/16

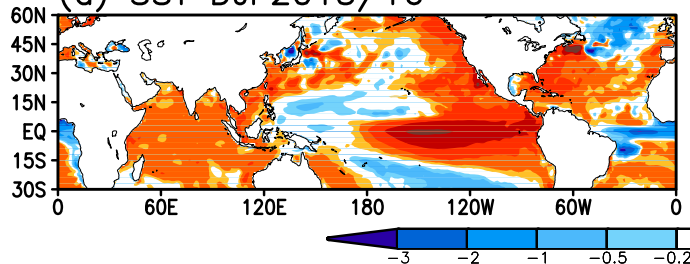

(b) SST DJF Comp

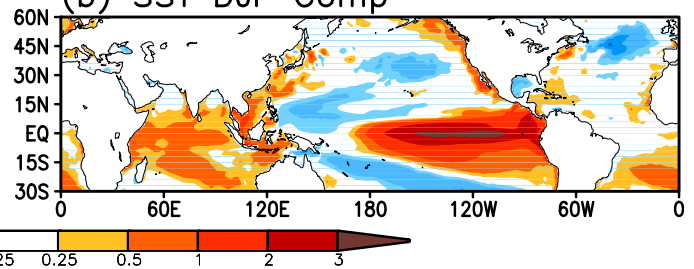

(c) Prec DJF2015/16

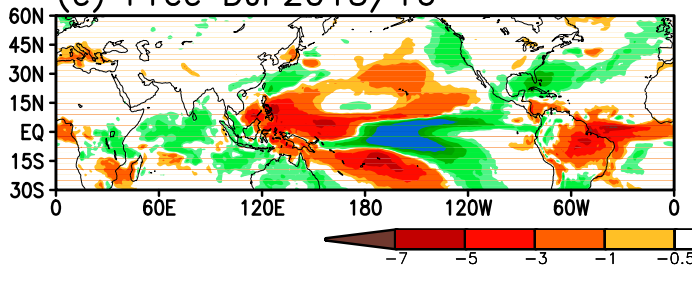

(d) Prec DJF Comp

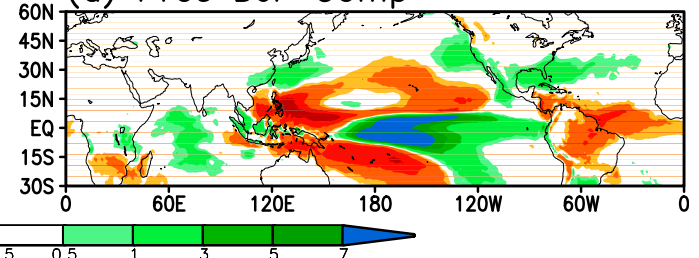

(e) z200 DJF2015/16

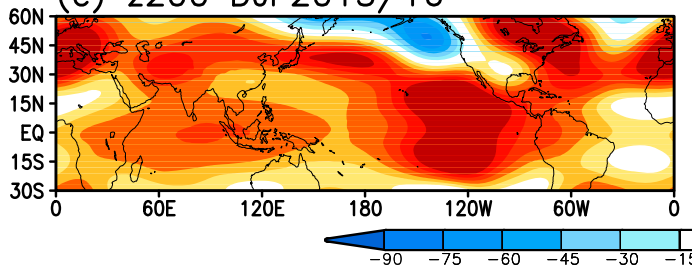

(f) z200 DJF Comp

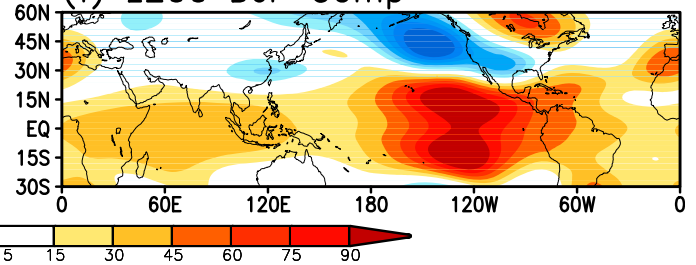

FIG. 3. (a),(c),(e) The CFSv2 ensemble mean forecasts of SST (K), precipitation ( $\mathrm{mm} \mathrm{day}^{-1}$ ), and $200-\mathrm{mb}$ height $(\mathrm{m})$ over the global region from $30^{\circ} \mathrm{S}$ to $60^{\circ} \mathrm{N}$ in DJF $2015 / 16$ and (b),(d),(f) their corresponding El Niño composites. The amplitudes of anomalies in the composite are adjusted to match that in DJF 2015/16 based on the Niño-3.4 SST index.

though the model anomalies are a response based on the average of 40 forecasts and the observed anomaly is equivalent to one forecast realization. This implies the dominance of SST forcing in constraining the tropical atmospheric variability.

Next, we analyzed the extratropical forecast atmospheric response to the forecast SSTs. Figure 4 shows CFSv2 ensemble means for DJF 2015/16 (left panels) and the model El Niño composites (right panels) for $200-\mathrm{mb}$ height over the PNA region $\left(20^{\circ}-70^{\circ} \mathrm{N}\right.$, $\left.180^{\circ}-60^{\circ} \mathrm{W}\right)$ and precipitation over the NA. In contrast to the tropics, the observed DJF 2015/16 atmospheric anomalies over the NA were not predicted well by the ensemble mean (left panels in Figs. 1 and 4). The correlation skill of the forecast ensemble means for DJF PNA 200-mb height and NA precipitation anomalies with observations are 0.69 and 0.23 (Table 2), respectively. The forecast ensemble means of NA atmospheric anomalies for DJF 2015/16 show that the subtropical Pacific jet was predicted to be toward the southern part of the West Coast and precipitation anomalies were strongly positive over the southwest NA and the West Coast. Although, this pattern differed from the observed DJF 2015/16 anomalies, except for the positive precipitation anomalies over the Pacific Northwest, it compared favorably with that of the predicted historical El Niño composite (right panels in Fig. 4). Indeed, the forecast ensemble means of PNA 200-mb height and

TABLE 2. As in Table 1, but for the correlations of CFSv2 ensemble means with the observed anomalies, and with the CFSv2 El Niño composite for DJF 2015/16, 1982/83, and 1997/98.

\begin{tabular}{lcccccc}
\hline \multicolumn{1}{c}{ Variable } & 2015/16-observed & 2015/16-composite & 1982/83-observed & 1982/83-composite & 1997/98-observed & 1997/98-composite \\
\hline SST (tropics) & 0.87 & 0.84 & 0.88 & 0.81 & 0.91 & 0.84 \\
Prec (tropics) & 0.68 & 0.85 & 0.83 & 0.84 & 0.79 & 0.70 \\
z200 (tropics) & 0.97 & 0.94 & 0.87 & 0.80 & 0.94 & 0.95 \\
z200 (PNA) & 0.69 & 0.87 & 0.79 & 0.72 & 0.73 & 0.60 \\
Prec (NA) & 0.23 & 0.78 & 0.55 & & \\
\hline
\end{tabular}



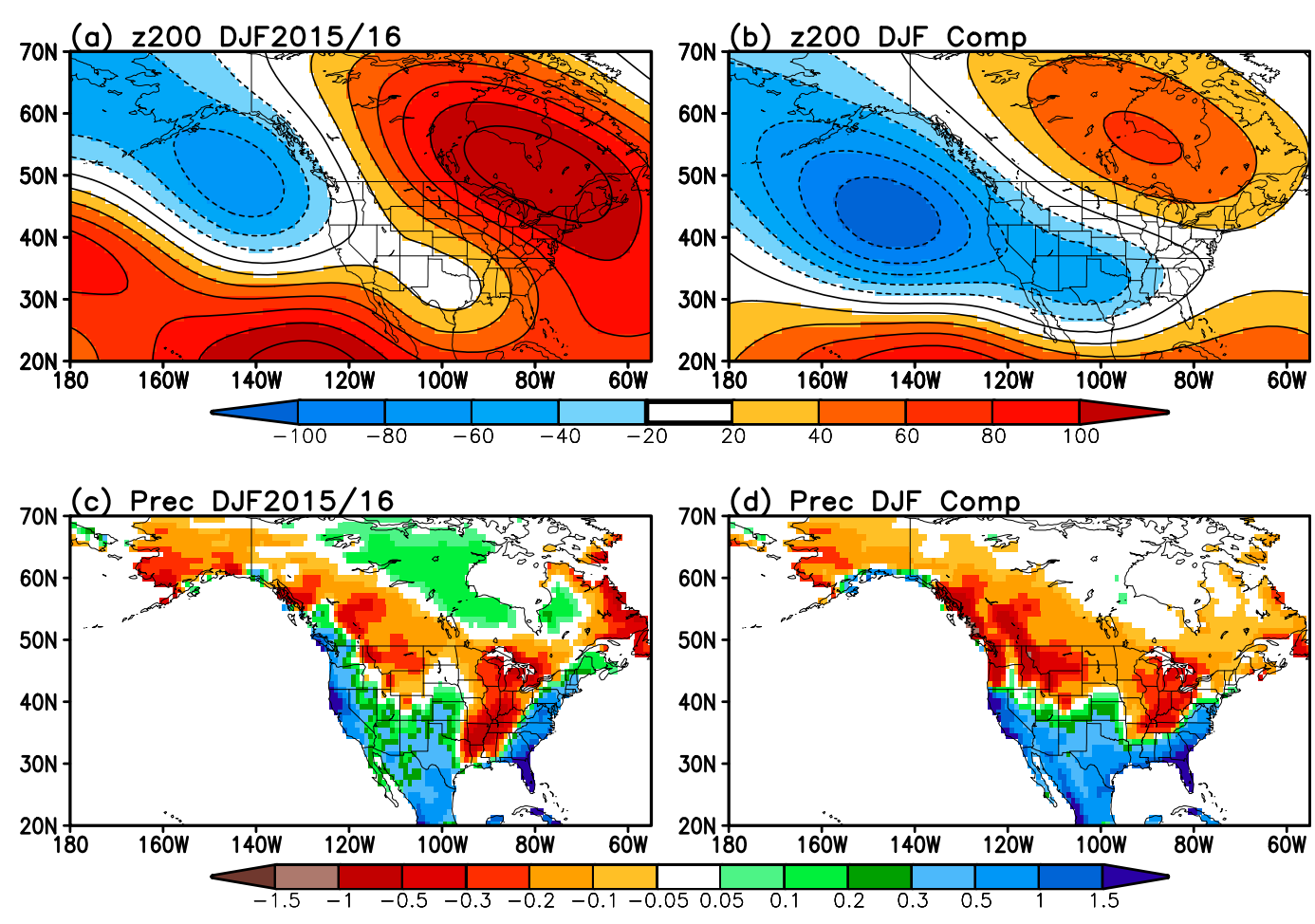

FIG. 4. As in Fig. 1, but for (a),(c) the CFSv2 ensemble mean forecasts for DJF 2015/16 and (b),(d) their corresponding forecast El Niño composites.

NA precipitation anomalies in DJF 2015/16 were well correlated with the corresponding El Niño composite (Table 2). The correlations are 0.87 and 0.78 for the PNA 200-mb height and NA precipitation, respectively. A high correlation implies that the pattern of forecast extratropical atmospheric response to SST forcing in DJF 2015/16 was similar to that of the mean El Niño signal in the historical period.

To further assess the similarity between that the ensemble mean forecast for DJF 2015/16 and the historical El Niño composite, the ensemble means of 200-mb height and precipitation for DJF 2015/16 is compared with that in previous extreme El Niño events of DJF 1982/83 and DJF 1997/98 (Fig. 5). In all three El Niño events, the pattern of atmospheric ensemble means were similar; the subtropical Pacific jet implied by the 200-mb height anomaly moved toward the U.S. Southwest, and the precipitation anomalies were positive over the southwest NA and were negative across the northern NA. The correlations of the ensemble mean forecast PNA 200-mb height of DJF 2015/16 to 1982/83, and to $1997 / 98$ are 0.94 and 0.93 , respectively and 0.80 and 0.78 for the NA precipitation (Table 3 ). This analysis also supports our previous comment that gradual changes in forcings should not result in a complete reversal of the atmospheric response pattern over the U.S. Southwest, a change from positive precipitation anomalies for the El Niño composite over the historical period to negative anomalies in the 2015/16 winter. Although the predicted pattern during all three events bear similarities, unlike for the 2015/16 event for which the model ensemble mean anomaly was opposite to the observed negative precipitation anomalies in the U.S. Southwest, the agreement for 1982/83 and 1997/98 with the observed NA precipitation was better (Fig. 5 and Table 2).

\section{c. Differences in atmospheric response during DJF 2015/16}

Although it indicates large similarities, the comparison of forecast DJF 2015/16 ensemble means with the forecast El Niño composite and with forecast ensemble means during 1982/83 and 1997/98, also has some differences. In this section we analyze those differences further and assess the influence they may have on the probability of outcomes of seasonal mean precipitation. The analysis is along the lines of Siler et al. (2017). A comparison with results from Siler et al. (2017) also highlights the possible model dependency in respective results.

In Fig. 6 the differences in forecast ensemble means of DJF 200-mb heights and precipitation for 1982/83, 1997/ 98, and 2015/16 from the scaled El Niño composites are shown. Based on the amplitude of the forecast Niño-3.4 
(a) 2200 DJF $1982 / 83$

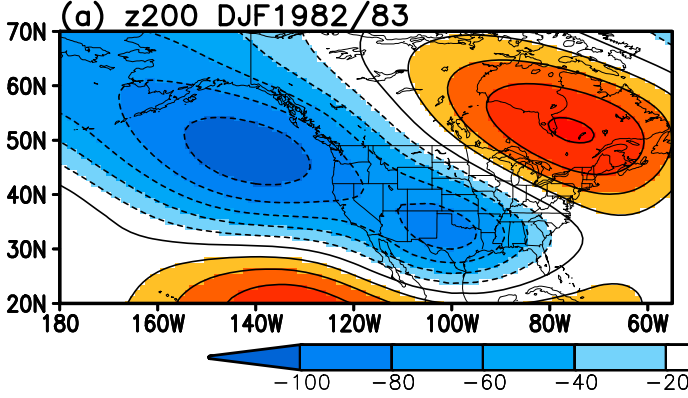

(b) z200 DJF1997/98

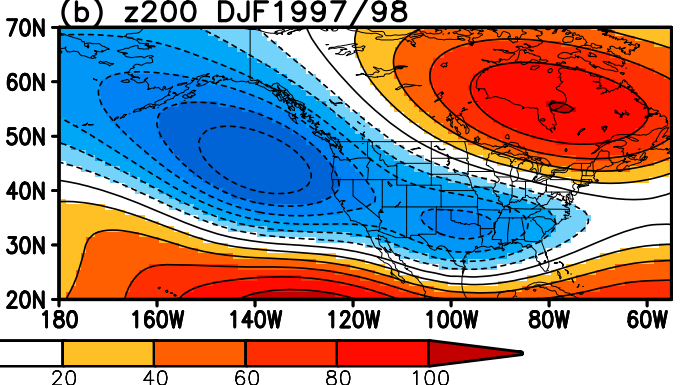

$70 \mathrm{~N}$ (c) Prec DJF1982/83

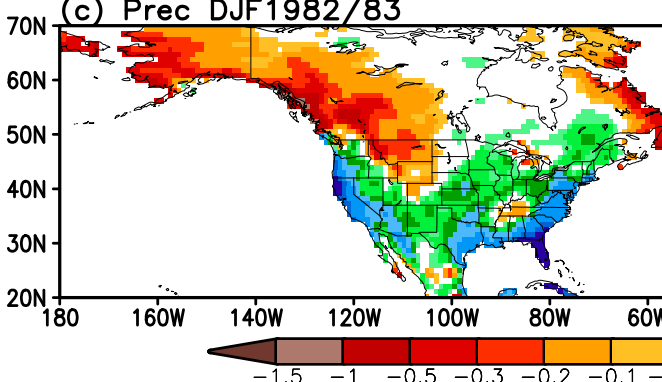

(d) Prec DJF 1997/98

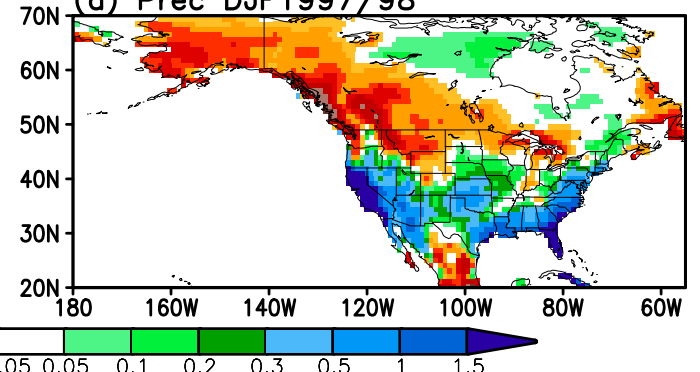

70N (e) Obs Prec DJF1982/83

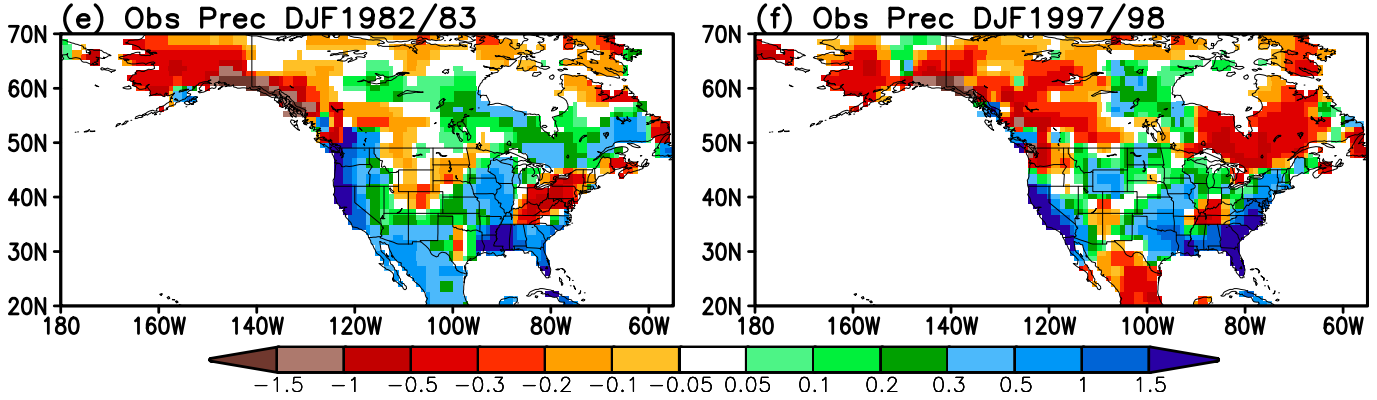

FIG. 5. (a),(b) The CFSv2 ensemble mean forecasts of 200-mb height (m) over the PNA region and (c),(d) precipitation $\left(\mathrm{mm} \mathrm{day}^{-1}\right)$ over North America, and (e),(f) the observed precipitation $\left(\mathrm{mm} \mathrm{day}^{-1}\right)$ over North America for DJF 1982/83 and 1997/98.

SST index the scaling factor for 1982/83, 1997/98, and 2015/16 was $1.78,2.05$, and 1.99 , respectively. To be consistent in comparing ensemble mean anomalies across different El Niño years, the ensemble mean of DJF 2015/16 includes only the 20 members initialized on 7, 12 , 17, 22, and 27 November, which are the same as for DJF $1982 / 83$ and 1997/98 forecasts from the hindcast data.

The forecast El Niño composite (Fig. 4, bottom right) had opposite sign precipitation anomalies along the U.S. West Coast with positive (negative) precipitation anomalies over California (Oregon/Washington). Although the seasonal mean forecast precipitation anomalies for all three events generally had positive anomalies along the U.S. West Coast (Figs. 4 and 5), their differences from the scaled El Niño composite has a pattern that is opposite in sign to the composite with a tendency toward negative (positive) precipitation over California (Oregon/Washington). This feature is consistent with the analysis of Hoerling and Kumar (2002) who noted that for strong El Niño events the seasonal mean precipitation anomalies tend to be positive along the entire U.S. West Coast. Such dependence in the precipitation response with the amplitude of El Niño SST anomaly will support a positive difference from the scaled El Niño composite in precipitation anomaly over Oregon/ Washington for the three strongest El Niño events. Further, a tendency for negative seasonal mean precipitation anomaly in the difference field from the scaled

TABLE 3. The spatial anomaly correlations of CFSv2 ensemble means of DJF 2015/16 with the ensemble means of DJF 1982/83, and DJF $1997 / 98$.

\begin{tabular}{lcc}
\hline \hline Variable & $2015 / 16-1982 / 83$ & $2015 / 16-1997 / 98$ \\
\hline z200 (PNA) & 0.94 & 0.93 \\
Prec (NA) & 0.80 & 0.78 \\
\hline
\end{tabular}



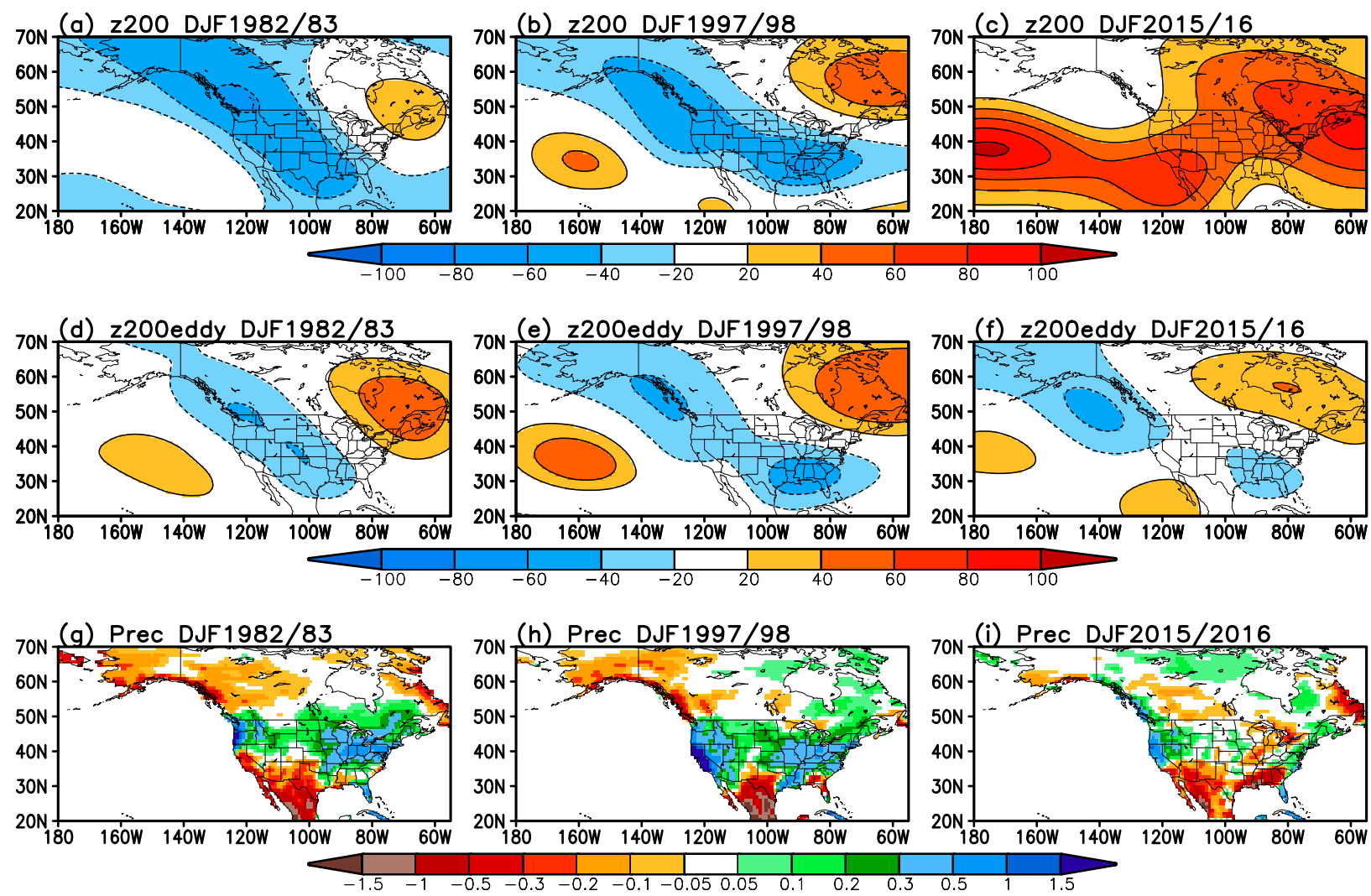

FIG. 6. The differences in forecast ensemble means of (a)-(c) DJF 200-mb heights (m), (d)-(f) the eddy component of the heights (m), and (g)-(i) precipitation $\left(\mathrm{mm} \mathrm{day}^{-1}\right.$ ) for 1982/83, 1997/98, and 2015/16 from the scaled El Niño composites from the CFSv2.

El Niño composite in the southern parts is indicative that the positive precipitation anomaly over these regions does not scale linearly with the Niño-3.4 amplitude, but rather shifts northward to cover Oregon/ Washington.

We also note that although the difference in DJF 2015/16 from the scaled composite has negative (positive) precipitation anomaly over California (Oregon/ Washington), which looks strikingly similar to the seasonal mean observed precipitation (Fig. 1), this similarity should not be construed as a result of some unique feature in SST forcing during 2015/16; a similar pattern for difference from the scaled composite is also found for 1982/83, although for which the observed precipitation anomaly was positive over the entire West Coast (Fig. 5). However, it is worth noting that there are differences in the details in the spatial pattern and the amplitude for the three El Niño years from the scaled composite. Such differences could be indicative of the sensitivity in precipitation response over the West Coast to details in the SST forcing that result in a departure from the linear response.

The difference for 200-mb heights from the scaled composite for three events (Fig. 6, top row), has a similar pattern for 1982/83 and 1997/98 but is strikingly different for $2015 / 16$. The largest difference for $2015 / 16$ is for positive heights between $30^{\circ}$ and $40^{\circ} \mathrm{N}$ that stretch across the entire domain in Fig. 6. A comparison of difference from the scaled composite after removing the zonal mean (Fig. 6, middle panel) shows better similarity in the departure of height response from the scaled El Niño composite for all three events. The dominance for the zonal component during 2015/16 could be due to warming trends in tropical SSTs resulting in higher 200-mb heights in recent decades, an influence that has a large zonally symmetric component. This influence can be seen in the evolution of DJF zonal mean 200-mb heights in observations and CFSv2 ensemble mean forecasts over the analysis period (see Fig. S1 in the online supplemental material). For both observations and CFSv2 forecasts, zonal mean height anomalies in the recent decade are higher, and further, this tendency is being pushed farther into higher latitudes in both hemispheres. A similar discussion in the context of tropical-extratropical teleconnection during La Niña events was noted by Kumar et al. (2010).

Following Siler et al. (2017), we next assess the change in area-averaged precipitation and its probability to be 

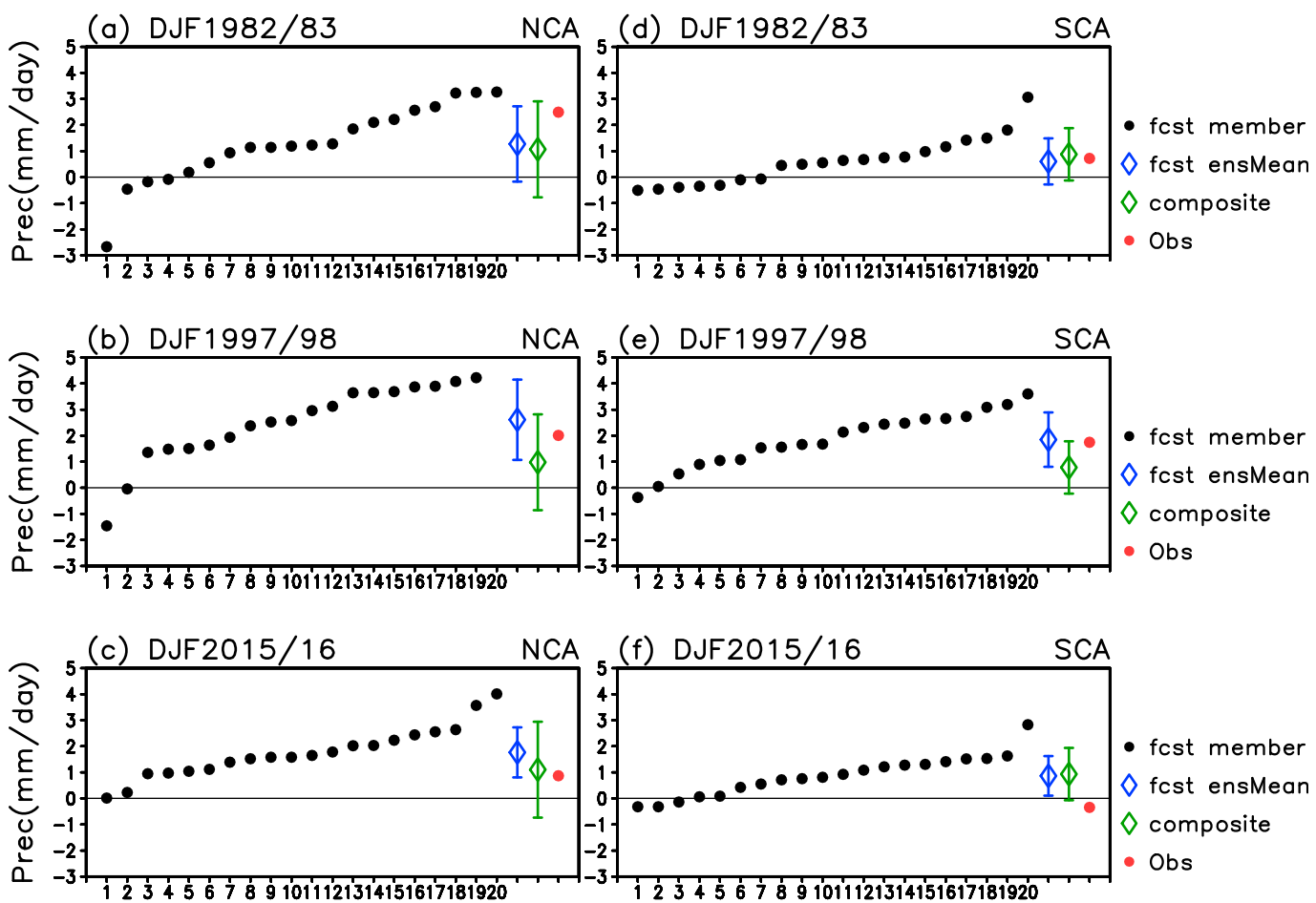

FIG. 7. The area-averaged precipitation anomalies over (a)-(c) Northern California (NCA) and (d)-(f) Southern California (SCA) for each forecast member (black dot), forecast ensemble mean (blue diamond), one standard deviation spread among individual forecast members (blue bar), observation (red dot), scaled El Niño composite (green diamond), and one standard deviation spread for DJF forecasts in 1982-2015 (green bar).

in the above-normal category over Northern and Southern California (referred to as NCA and SCA). The latitudinal boundary between NCA and SCA is taken as $38^{\circ} \mathrm{N}$ to follow Siler et al. (2017).

The area-averaged rainfall over NCA for all three El Niño events is shown in Figs. $7 \mathrm{a}-\mathrm{c}$ and each panel includes the following: area-averaged precipitation anomaly for each forecast member (black dot), ensemble mean forecast anomaly (blue diamond), spread in forecast anomaly quantified as the unit standard deviation of spread in precipitation among individual forecast members (blue bar), observed precipitation anomaly (red dot), precipitation anomaly based on scaled El Niño composite (green diamond), and one standard deviation spread for DJF forecasts based on the entire sample (i.e., the climatological spread in forecast DJF from November initial conditions) (green bar). A similar analysis for SCA is shown in Figs. 7d-f.

Below we note salient features in Fig. 7 and their comparison with Siler et al. (2017).

- There is large forecast-to-forecast variability in the area-averaged precipitation anomaly over NCA and SCA, and in contrast to the ensemble mean that is positive, there are some forecast members that also have negative precipitation values. A similar spread in seasonal mean precipitation was evident in results of Siler et al. (2017). A difference from the results from Siler et al. (2017) may be that in their case many more forecast members have negative seasonal mean precipitation anomaly (see their Fig. 3). In section 3d, this aspect of member-to-member variability in precipitation is discussed in more detail.

- The ordering of area-averaged ensemble mean precipitation anomalies across three events from the lowest to the highest value (i.e., 1982/83, 2015/16, and 1997/98) is the same as ordering of the amplitude of Niño-3.4 SSTs. This result is to be expected if the atmospheric response to SSTs is dominated by the linear component. The amplitude scaling, however, does not strictly follow the SST amplitude. For example, precipitation anomalies during 1997/98 are much larger than for other two events (see Table 4).

- Unlike Siler et al. (2017), neither over NCA nor SCA, the area-averaged ensemble mean precipitation anomaly for 2015/16 is smallest among the three events; in our analysis the lowest value is for 1982/83. The precipitation anomaly is the largest for 1997/98 both over NCA and SCA in our analysis, while this is the case for NCA only in Siler et al. (2017). We note 
TABLE 4. The Northern and Southern California (NCA and SCA) area-averaged ensemble mean precipitation and scaled El Niño composite anomalies, and their corresponding probability to be in the above-normal category for DJF 1982/83, 1997/98, and 2015/16. For more details, refer to the text.

\begin{tabular}{|c|c|c|c|c|}
\hline & $\begin{array}{c}\text { Ensemble mean } \\
\text { anomaly }\left(\mathrm{mm} \mathrm{day}^{-1}\right)\end{array}$ & Probability & $\begin{array}{c}\text { Scaled composite } \\
\text { anomaly }\left(\mathrm{mm} \mathrm{day}^{-1}\right)\end{array}$ & Probability \\
\hline \multicolumn{5}{|c|}{ NCA climatology PDF spread $=1.84 \mathrm{~mm} \mathrm{day}^{-1}$} \\
\hline DJF $1982 / 83$ & 1.28 & $61 \%$ & 1.07 & $56 \%$ \\
\hline DJF $1997 / 98$ & 2.61 & $84 \%$ & 0.98 & $54 \%$ \\
\hline DJF 2015/16 & 1.76 & $70 \%$ & 1.11 & $57 \%$ \\
\hline \multicolumn{5}{|c|}{ SCA climatology PDF spread $=1.00 \mathrm{~mm} \mathrm{day}^{-1}$} \\
\hline DJF $1982 / 83$ & 0.61 & $57 \%$ & 0.87 & $67 \%$ \\
\hline DJF 1997/98 & 1.85 & $92 \%$ & 0.78 & $64 \%$ \\
\hline DJF 2015/16 & 0.87 & $67 \%$ & 0.93 & $69 \%$ \\
\hline
\end{tabular}

that such comparison between numerical values is sensitive to model resolution (and also the spatial resolution of the model output analyzed) and to the precise definition of area included in the NCA and SCA. Nonetheless, differences in the results point to a lack of consistency between our results and Siler et al. (2017).

Next, we attempt to quantify the change in probability for the area-averaged precipitation anomaly based on ensemble mean responses for three El Niño events and compared them with the probability implied by linearly scaling the El Niño composite. The procedure of computing the respective probabilities is as follows:

- First, the standard deviation of DJF forecasts is computed from all the available DJF forecast data (1982-2015) for November initial conditions. It is the green bar in Fig. 7. We assume that this estimate of standard deviation is the standard deviation of climatological distribution of forecast seasonal mean precipitation, and that the probability distribution function (PDF) of seasonal mean rainfall is Gaussian (Kumar and Chen 2017). This computation is done separately for the area-averaged precipitation over NCA and SCA.

- Based on above assumptions, below- and abovenormal tercile boundaries for DJF forecast over NCA and SCA are computed.

- In addition, making an assumption that the spread of PDF does not change from event to event (Kumar et al. 2000; Peng and Kumar 2005; Tippett et al. 2004; Chen and Kumar 2015), the PDF of precipitation for each El Niño event is recentered over the forecast ensemble mean anomaly. For the case of the El Niño composite, the PDF is recentered over the scaled composite value.

- Next, the probabilities for the precipitation anomalies of the ensemble mean and scaled composite to be in the above category are computed. The values for NCA and SCA are summarized in Table 4.
Although the above assumptions are well supported by many previous studies, we have not assessed the reliability for the estimates of forecast probability thus compute. Such an analysis would require an assessment of forecasts over the entire available history, for example, as presented by Peng et al. (2013).

For both NCA and SCA, the probability of precipitation to be in the above-normal category based on the scaled El Niño composite for all three events is for larger than the climatological value of $33.33 \%$, and further, the probability values themselves are similar. The probability values are also higher over the SCA. Higher than climatological probabilities for the abovenormal category is consistent with the positive precipitation anomaly for the El Niño composite (Fig. 4).

Based on the forecast ensemble mean response for three individual events, the assessment of probabilities to be in the above-normal category has a tendency for the probabilities to be larger than the estimate based on the scaled composite over NCA. This result could be anticipated from the sign of difference in DJF precipitation for each event from the scaled composite (Fig. 6). Over SCA, the probabilities for 1982/83 and 2015/16 are somewhat lower than indicated by the scaled El Niño composite, while they are higher for 1997/98. What we would like to emphasize is that the probability values for 2015/16 do not indicate a marked decrease in seasonal mean precipitation to be in the above-normal category (and by inference, an increase in probability to be in the below-normal category). We also note that if we were to use the spread in forecasts for 2015/16 (instead of climatological spread) to estimate the probabilities, it would have resulted in a higher probability estimate for seasonal mean precipitation to be in the above-normal category. This is because the estimate of spread for 2015/16 (blue bars in Fig. 7f) is smaller than the climatological spread (green bar in Fig. 7f). Our results, therefore, contrast with the results of Siler et al. (2017) and could be a consequence of model 
dependence in the atmospheric response to SSTs or could be due to some caveat associated with the analysis of initialized coupled prediction (as done here) and possible errors in SST predictions.

A lack of consistency in the area-averaged anomalies across three strong El Niño events with results from Siler et al. (2017) highlights the fact that reaching an understanding for the reasons of differences in CFSv2 response in DJF 2015/16, either from the composite El Niño pattern or from the response during other extreme El Niño winters (DJF 1982/83 or DJF 1997/98), will be a difficult task and will require one to overcome issues related to model dependency in responses, and sampling (that to a certain extent, can still influence the stability of ensemble mean response).

Pursuing a thorough understanding for differences in CFSv2 response in DJF 2015/16 when compared to the composite $\mathrm{El} \mathrm{Niño}$, either because of the uniqueness of forcings (the flavors of El Niño or SSTs in other ocean basins or anomalies in land or other terrestrial conditions) or because of changes in El Niño teleconnection under increasing influence of $\mathrm{CO}_{2}$, would also call for a different experimental setup where individual forcings can be controlled and large ensembles (preferably using multiple models) can be generated to isolate the influence of each [e.g., the approach followed in Siler et al. (2017)]. However, a question of practical relevance in real-time seasonal forecasting, and use of forecasts in decision-making is that even if differences in response that were unique to forcings in DJF 2015/16 existed, were such differences robust enough to anticipate differences in the observed seasonal mean precipitation anomaly (Fig. 1c) and the corresponding El Niño composite (Fig. 1d)?

In summary, the analysis of the atmospheric response to forecast SSTs based on the ensemble mean forecast led to the following conclusions:

- The tropical forcings for the global circulation were predicted well for the DJF 2015/16.

- The predicted teleconnection pattern in 200-mb height, and further, the response pattern in precipitation in DJF 2015/16 were similar to the mean El Niño signal from the historical period. This was true for the response pattern in both tropical and extratropical latitudes.

- Based on model results, although some differences from the composite El Niño response existed, it will be hard to conclude that the observed negative precipitation anomalies over the southwest NA in DJF 2015/16 were because of the dominant influence from changes in the forced response. Further, even if alternate forcings-SST anomalies in other ocean basins, soil moisture anomalies over California, changes in anthropogenic forcing-may be responsible for some deviation from the composite El Niño response, since these factors were included in the CFSv2 forecasts, it is unlikely that these influences can account for reversal in the observed seasonal mean DJF 2015/ 16 precipitation anomalies to be opposite of the El Niño composite.

The reason why the observed DJF 2015/16 NA atmospheric anomalies differed so dramatically from the canonical El Niño signal in the Southwest precipitation could also be the result of random contribution of the variability associated with the atmospheric noise. To analyze this, following the methodology used in Kumar et al. (2013) we next assess the possible contribution of atmospheric noise to the outcome of observed DJF 2015/16 anomalies.

\section{d. Contribution of atmospheric noise to individual forecasts}

Figure 8 shows the spatial correlation between the observed anomaly and individual forecasts for DJF 2015/16 precipitation over the NA (Fig. 8a) and SST over oceans in $30^{\circ} \mathrm{S}-60^{\circ} \mathrm{N}$ (Fig. 8b). The correlations are for all 40 forecast members initialized in the last 10 days of November 2015 (i.e., the same members that went into ensemble means shown in Figs. 2-4). The NA precipitation correlations are arranged in an ascending order. The correlations for global SST are not arranged in ascending order but correspond to the same forecast member for which the NA precipitation correlation is shown. The purpose is to demonstrate that changes in the spatial pattern of predicted precipitation over NA (relative to observations) were not a response to changes in spatial pattern of predicted SSTs. This inference can be drawn based on the recognition that the forecast members of NA precipitation with lower (higher) correlation skills do not have lower (higher) SST correlation skills. The correlation skill of NA precipitation for each of 40 members is low and has large variations; the lowest correlation is -0.22 and the highest one is 0.5 . The correlation of global SST, on the other hand, is high (about 0.8) and similar among each of 40 members.

This analysis clearly indicates that even with forecast SSTs that are close to the observation, there could be an appreciable range of seasonal mean precipitation outcome over NA. The atmospheric internal variability (or the unpredictable noise), therefore, alone could cause large variations in the outcomes for seasonal means in extratropical latitudes. Therefore, there is a strong possibility that difference between the observed DJF 2015/16 anomalies and the mean El Niño signal over the southwest NA was a consequence of random atmospheric noise. 

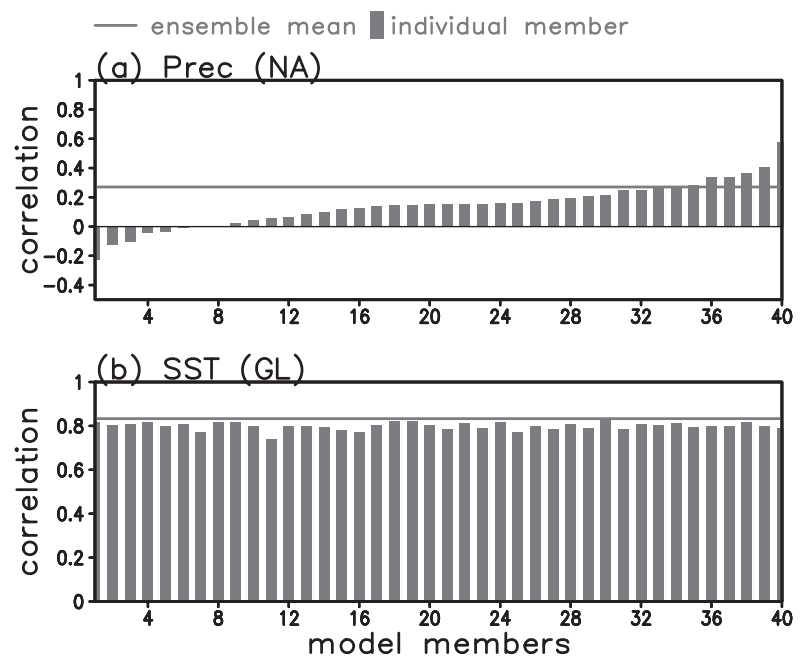

FIG. 8. Spatial anomaly correlation between the observed anomaly and individual members of 40 ensemble forecasts of DJF 2015/16 initialized in the last 10 days of November 2015 for (a) precipitation over North America and (b) SST over the region in $30^{\circ} \mathrm{S}-60^{\circ} \mathrm{N}$. The NA precipitation correlations are arranged in an ascending order. The order of forecast members for SST is corresponding to the same forecast member as for the NA precipitation.

Based on the NA precipitation correlation skill for each individual member shown in Fig. 8, the spatial distributions of the four members with the lowest correlation skills are further compared to that of four members with the highest correlation skills to demonstrate the role of atmospheric internal variability on seasonal mean outcomes over NA precipitation in DJF 2015/16. The corresponding averages of the four best and four worst forecasts, and their difference for the PNA 200-mb height, the NA precipitation, tropical and northern extratropical SST, and precipitation are shown in Fig. 9. Important points to note are as follows: subtle changes in the location and direction of the Pacific jet in the forecast heights can have large implications for precipitation, although some of the variations in seasonal mean precipitation can also be associated with other factors (e.g., land surface coupling, the occurrences of local events, or influence from atmospheric rivers over the NE Pacific).

The forecasts for the PNA 200-mb height show the subtropical Pacific jet for the four best forecasts to be located slightly more north than that for the four worst forecasts. However, the four members of NA precipitation with the lowest correlation skills are very different from the four members with the highest correlation skills. Furthermore, the precipitation anomaly amplitude in the mean of the four members with the highest correlation skills (i.e., the four members closest to the observation), is of the same order as the observed DJF 2015/16 precipitation anomaly over the U.S. Southwest (Fig. 1c), while for the four worst forecasts it is opposite of the observed seasonal mean anomaly. The differences in SST anomalies between the four best and four worst forecasts are very small with the absolute differences less than $0.25 \mathrm{~K}$ over most of the oceans; the differences in their precipitation forecasts over the tropics are also small (and are random). This is consistent with small differences in predicted SSTs in tropical latitudes from one forecast to another. The atmospheric internal variability, therefore, alone could be responsible for large changes in the seasonal mean circulation in observed DJF 2015/16, and such variations cannot be anticipated on a seasonal time scale.

One could argue that the amplitude of the internal variability in DJF 2015/16 in observations may have been unusually large compared to that in the winters of 1982/83 and 1997/98, and may have had a higher likelihood of contributing to seasonal mean anomalies (thereby making the prospects for a good prediction harder). Although this cannot be verified from the observational analysis alone, one can compare the amplitude of internal variability in forecasts during three extreme El Niño events. To quantify the noise in forecasts, we calculated the spread among forecast members for three El Niño events. (As shown in Fig. S2, the patterns and magnitudes of the spreads in the ensemble of forecasts are similar among all three events.) This result is consistent with previous results that in response to interannual variations in ENSO SSTs, the year-to-year changes in the spread among ensemble members are relatively small compared to changes in ensemble mean anomalies (Kumar et al. 2000; Chen and Kumar 2015), and the dominant contributor to predictability on seasonal time scales comes from variations in ensemble mean.

It could still be argued that the small differences in SSTs shown in Fig. 9 may be a relevant factor in forcing forecast-to-forecast variations in extratropical circulation. To substantiate that it is not so, the monthly forecasts with the shortest leads is used to reconstruct the seasonal mean, and thereby, further reduce the errors in the forecasts for SST and tropical precipitation. Specifically, the synthesized seasonal mean forecast of DJF 2015/16 is the average of the sum of the shortest lead monthly forecasts from the last 10 days (i.e., 40-member forecasts) of November 2015 (for the month of December 2015), December 2015 (for the month of January 2016), and January 2016 (for the month of February 2016), respectively. By constructing the seasonal mean from three individual monthly forecasts with the shortest lead initializations, the reconstructed seasonal mean is influenced more by the atmospheric and land initial conditions, and the errors in the seasonal mean forecasts associated with tropical forcings are further reduced. 

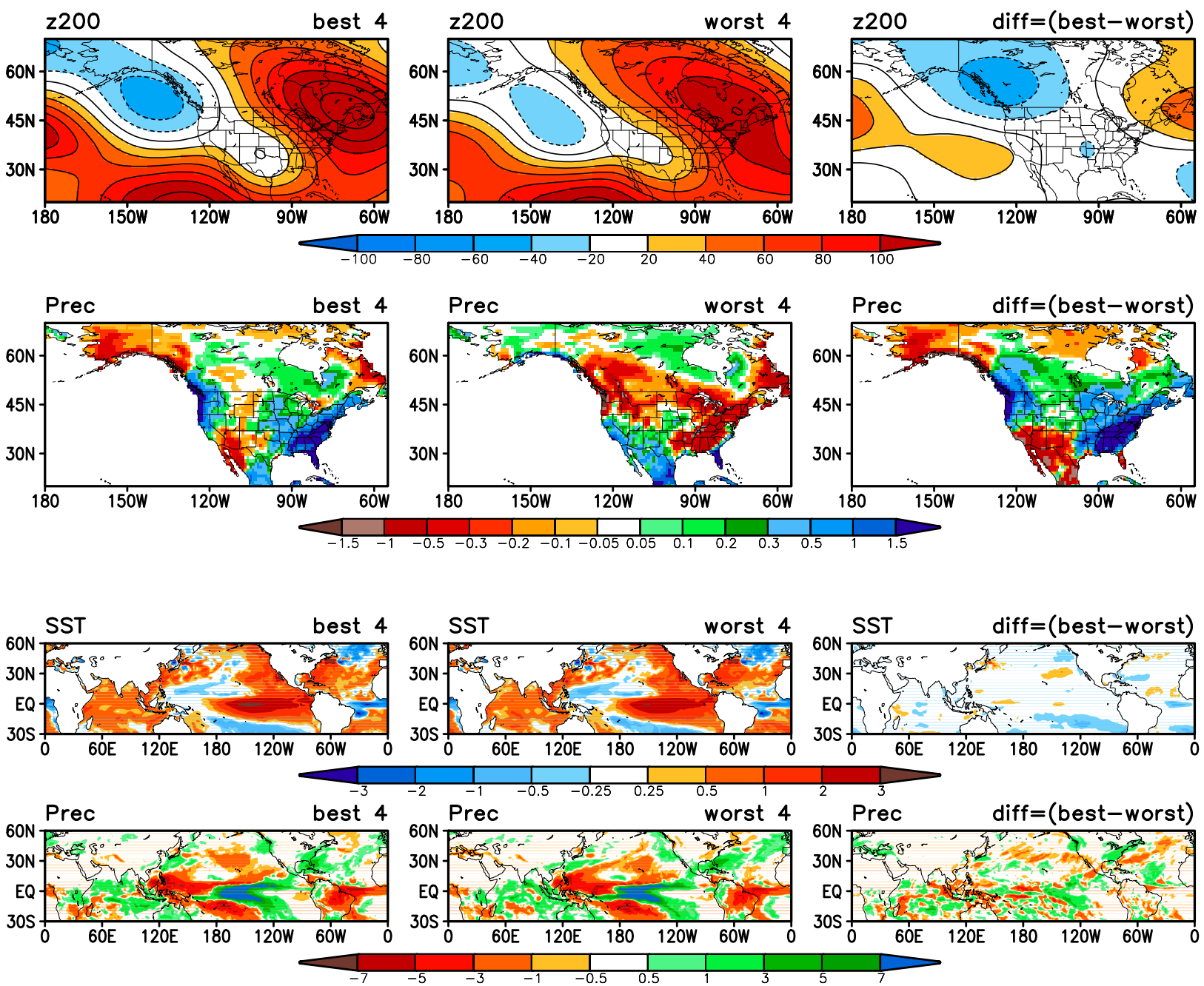

FIG. 9. Average of (left) four best forecast members, (middle) four worst forecast members, and (right) their differences for DJF 2015/16 forecasts from CFSv2. (from top to bottom) The 200-mb height $(\mathrm{m})$ over the PNA, precipitation (mm day ${ }^{-1}$ ) over North America, SST $(\mathrm{K})$, and precipitation $\left(\mathrm{mm} \mathrm{day}^{-1}\right.$ ) over the region from $30^{\circ} \mathrm{S}$ to $60^{\circ} \mathrm{N}$.

Similar to the format shown in Fig. 9, Fig. 10 shows the spatial maps of NA precipitation, 200-mb height, and tropical SST and precipitation based on the synthesized seasonal mean forecasts of DJF 2015/16. The differences in SSTs between the four members with the lowest correlations and that with the highest correlations are further reduced relative to those shown in Fig. 9. However, the magnitude of the differences in PNA 200-mb height (z200) and the NA precipitation anomalies is still at the same level as that in Fig. 9. This provides further confirmation that it is the random noise in atmospheric variability, not the differences in SST forecasts, which caused the large differences in the NA precipitation shown in Fig. 9.

In summary, the differences in the precipitation anomalies among the best four (with negative anomalies) and the worst four (with positive anomalies) forecasts over the U.S. Southwest are due to the atmospheric internal variability. Similarly, one can also argue that the differences in the precipitation anomalies for the best four forecasts (Fig. 9) from the ensemble mean response to the SSTs (Fig. 4) are also due to the influence of random, and unpredictable atmospheric noise associated with the atmospheric internal variability. By construct, because the precipitation anomalies in the best four members agree well with the observed DJF 2015/16 precipitation anomalies, one can infer that differences in the observed DJF 2015/16 precipitation anomalies from the El Niño composite response could also have been a consequence of atmospheric noise.

\section{Summary and discussion}

In this study, the possible reasons for the observed winter 2015/16 precipitation anomalies that were opposite 

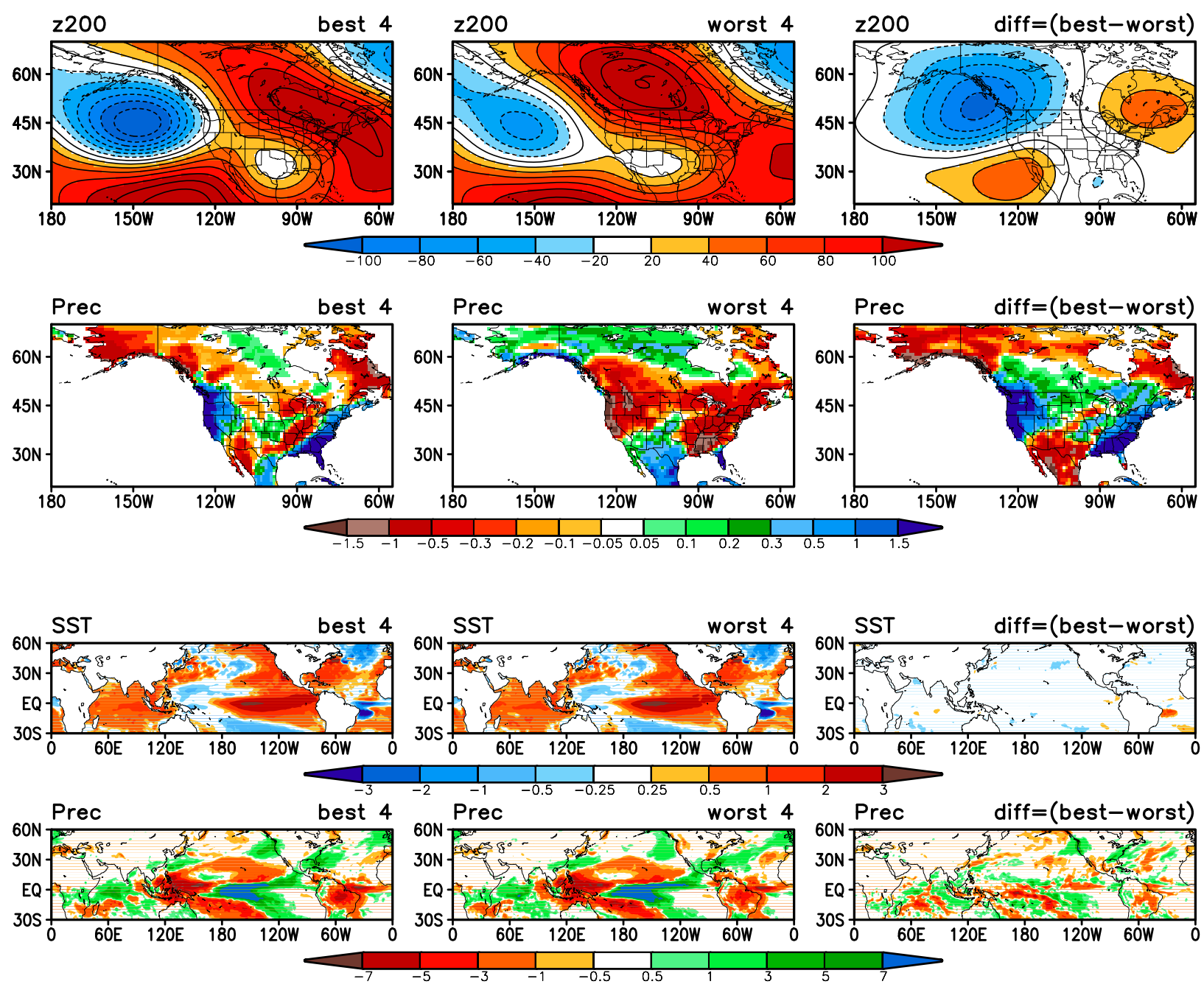

FIG. 10. As in Fig. 9, but for the constructed seasonal mean forecasts of DJF 2015/16.

to the mean El Niño signal over southwest North America were analyzed. The analysis focused on the role of SST forcing and the contributions of atmospheric internal variability. To overcome the limitation of the sampling that is inherent in the observation based analysis, the analysis also relied on the ensemble of forecasts from the NCEP Climate Forecast System, version 2 (CFSv2). The ensemble-based analysis was used to address the question to what extent the differences in the observed DJF 2015/16 anomalies over the NA and the historical El Niño composite were influenced by differences in atmospheric response to SST (that were specific to this season and differed from the historical El Niño composite) and other external forcings, and what differences could have been due to the contribution of unpredictable atmospheric noise.

We first analyzed the atmospheric response to forecast SSTs based on the ensemble mean. Specifically (i) we examined how well the observed 2015/16 winter NA atmospheric anomalies were predicted as an ensemble mean atmospheric response, and (ii) if the pattern of 2015/16 winter anomalies in the forecast ensemble mean was different from that of the El Niño composite. We then assessed the contribution of atmospheric noise based on individual forecast members to examine how much the individual forecasts can differ from the ensemble means, and if the observed 2015/16 winter atmospheric anomalies were within the envelope of variability in the ensemble of forecast.

The results show that the pattern of 2015/16 winter ensemble mean atmospheric response in model forecasts over NA to SSTs compared favorably with the El Niño composite from the historical period. The model forecast response was also similar to the previous El Niño events of 1982/83 and 1997/98. We also analyzed differences from the El Niño composite response, and 
from the forecast response in 1982/83 and 1997/98. Our results, however, were not consistent with those reported by Siler et al. (2017) in that differences in the response in our analysis were not large enough to alter the probabilities of seasonal mean outcome to the extent of making the observed precipitation over California as a much more likely event. Therefore, even though there were differences in DJF 2015/16 SSTs from the canonical El Niño, such differences cannot easily account for the reversal of the observed seasonal mean precipitation anomalies from the El Niño composite. Based on this result, we inferred that the observed negative precipitation anomalies over the southwest NA in DJF 2015/16 were not overwhelmingly influenced by changes in response to the SST and other external forcings.

The analysis of the ensemble of DJF 2015/16 forecasts based on 40 members from the latest initial conditions also allowed us to quantify that there were considerable variations in the outcome of the 2015/16 winter precipitation over North America from one forecast to another even though the forecast SSTs in the equatorial Pacific were the same. The differences in the NA precipitation between the averages of the four worst and four best forecast members in the 40 ensemble forecasts were large, and the sign of the precipitation anomalies of the worst four forecasts was reversed in comparison to that of the best ones over the large portions of NA. The amplitude of precipitation anomalies for the composite of the best four members was at the same level as that of the observation. Therefore, the observed 2015/16 anomalies were within the envelope of ensemble of forecasts. The observed negative precipitation anomalies over the U.S. Southwest, which were opposite to the El Niño signal, could be a result of a large contribution from the internal atmospheric processes alone.

In conclusion, the reason why the observed 2015/16 winter precipitation anomalies over the U.S. Southwest differed from the El Niño composite could easily have been due to the large contribution of the atmospheric internal, and unpredictable, variability interfering with the atmospheric response to the ENSO SSTs.

The results in this study are similar to results in Quan et al. (2018). Based on the analysis of AMIP and CMIP simulations Quan et al. (2018) also found that the El Niño teleconnection patterns in 2015/16 and 1982/83 were similar and the ensemble mean precipitation anomalies over the U.S. Southwest were positive for both events. In the current study, the analysis was based on a single seasonal prediction system-CFSv2. It would be desirable to do a similar analysis with other forecast systems, for example, those participating in the North America Multimodel Ensemble (NMME; Kirtman et al. 2014). A more comprehensive approach will also involve analysis along the methodology used by Siler et al. (2017) and Paek et al. (2017) (where SST forcings can be controlled) but using a multimodel AMIP approach.

We also note that in our analysis no attempt was made to remove the trend. We anticipate that trend will mostly influence tropical and subtropical heights (as is evident in Figs. 2 and 3 when comparing the DJF 2015/16 heights with the composites). As there is no significant trend in NA precipitation (Deser et al. 2012; Hu et al. 2012; Hoerling et al. 2013), the conclusions drawn in the current analysis should be the same with the analysis based on the data with the trend removed.

A criticism to our analysis, and conclusions, can be that the analysis did not consider the possibility of forcings other than SSTs, the influence of which could have altered the atmospheric response that led to the NA pattern observed in DJF 2015/16. Such forcings could include extreme dry conditions over California (Seager et al. 2015). Demonstrating validity of such a hypothesis will require an extensive set of model experiments, but to counter such possibilities we offer the following arguments:

- The current generation of seasonal forecast systems includes realistic initial conditions for various boundary forcings. For example, this is true for CFSv2 and other models in the NMME that were initialized from the dry land surface conditions over California, yet failed to predict a precipitation signal substantially different from the canonical El Niño response.

- The long history of analyzing the predictability of seasonal mean climate variability has repeatedly concluded that the variability associated with ENSO SSTs is the dominant source of seasonal predictability. So far, other systematic sources of seasonal predictability have yet to be identified, especially, for the prediction of the North America precipitation.

- The dominance of the atmospheric internal variability in extratropical latitudes is a fact that is often ignored as the biggest limiting factor for the skill for extended range predictions. The importance of atmospheric internal variability is easily documented from forecast-to-forecast variability in seasonal mean anomalies within the ensemble of forecasts, and by model simulations where even all external forcings are held fixed, yet outcomes of seasonal means can differ substantially (Kumar et al. 2013). In fact, the genesis of the ensemble forecasting approach is our desire to sample the spread in the forecast outcomes that is due to atmospheric internal variability resulting from the nonlinear evolution of small differences in the specification of initial conditions. The nonlinear evolution 
of errors in the specification of initial conditions, and resulting divergence among forecasts within the ensembles, affects forecasts on all time scales (Kumar and Murtugudde 2013). The acceptance of the ensemble prediction approach implicitly recognizes the role of the importance of atmospheric internal variability on forecast outcomes (Kumar and Chen 2015), and that observed seasonal mean anomalies can differ from the ensemble mean signal.

Acknowledgments. We would like to thank the editor, Dr. Caihong Wen, Dr. Hui Wang, and two anonymous reviewers for their constructive comments.

\section{REFERENCES}

Barnston, A. G., and T. M. Smith, 1996: Specification and prediction of global surface temperature and precipitation from global SST using CCA. J. Climate, 9, 2660-2697, https://doi.org/10.1175/1520-0442 (1996)009<2660:SAPOGS $>2.0$. CO;2.

Barsugli, J. J., and P. D. Sardeshmukh, 2002: Global atmospheric sensitivity to tropical SST anomalies throughout the IndoPacific basin. J. Climate, 15, 3427-3442, https://doi.org/ 10.1175/1520-0442(2002)015<3427:GASTTS >2.0.CO;2.

Becker, E., and H. van den Dool, 2016: Probabilistic seasonal forecasts in the North American Multimodel Ensemble: A baseline skill assessment. J. Climate, 29, 3015-3026, https:// doi.org/10.1175/JCLI-D-14-00862.1.

Bond, N. A., M. F. Cronin, H. Freeland, and N. Mantua, 2015: Causes and impacts of the 2014 warm anomaly in the NE Pacific. Geophys. Res. Lett., 42, 3414-3420, https://doi.org/ 10.1002/2015GL063306.

Chen, M., and A. Kumar, 2015: Influence of ENSO SSTs on the spread of the probability density function for precipitation and land surface temperature. Climate Dyn., 45, 965-974, https:// doi.org/10.1007/s00382-014-2336-9.

— W. Wang, and A. Kumar, 2010: Prediction of monthly mean temperature: The roles of atmospheric and land initial condition and sea surface temperature. J. Climate, 23, 717-725, https://doi.org/10.1175/2009JCLI3090.1.

DelSole, T., and J. Shukla, 2006: Specification of wintertime North American surface temperature. J. Climate, 19, 2691-2716, https://doi.org/10.1175/JCLI3704.1.

Deser, C., A. S. Phillips, C. Bourdette, and H. Teng, 2012: Uncertainty in climate change projections: The role of internal variability. Climate Dyn., 38, 527-546, https://doi.org/10.1007/ s00382-010-0977-x.

Dole, R., and Coauthors, 2014: The making of an extreme event: Putting the pieces together. Bull. Amer. Meteor. Soc., 95, 427440, https://doi.org/10.1175/BAMS-D-12-00069.1.

Guo, P., P. A. Dirmeyer, and T. DelSole, 2011: Land surface impacts on subseasonal and seasonal predictability. Geophys. Res. Lett., 38, L24812, https://doi.org/10.1029/2011GL049945.

Hartmann, D. L., 2015: Pacific sea surface temperature and the winter of 2014. Geophys. Res. Lett., 42, 1894-1902, https:// doi.org/10.1002/2015GL063083.

Hoerling, M., and A. Kumar, 2002: Atmospheric response patterns associated with tropical forcing. J. Climate, 15, 2184-2203, https://doi.org/10.1175/1520-0442(2002)015<2184: ARPAWT $>2.0 . \mathrm{CO} ; 2$.
, and Coauthors, 2013: Anatomy of an extreme event. J. Climate, 26, 2811-2832, https://doi.org/10.1175/JCLI-D-12-00270.1.

Horel, J. D., and J. M. Wallace, 1981: Planetary-scale atmospheric phenomenon associated with the Southern Oscillation. Mon. Wea. Rev., 109, 2080-2092, https://doi.org/10.1175/1520-0493 (1981)109<2080:ARPCAO>2.0.CO;2.

Hu, Z.-Z., A. Kumar, and B. Huang, 2012: An analysis of forced and internal variability in a warmer climate in CCSM3. J. Climate, 25, 2356-2373, https://doi.org/10.1175/JCLI-D-11-00323.1.

,-- , B. Jha, J. Zhu, and B. Huang, 2017: Persistence and predictions of the remarkable warm anomaly in the northeastern Pacific Ocean during 2014-16. J. Climate, 30, 689-702, https://doi.org/10.1175/JCLI-D-16-0348.1.

Janowiak, J. E., and P. Xie, 1999: CAMS-OPI: A global satelliterain gauge merged product for real-time precipitation monitoring applications. J. Climate, 12, 3335-3342, https://doi.org/ 10.1175/1520-0442(1999)012<3335:COAGSR > 2.0.CO;2.

Jha, B., A. Kumar, and Z.-Z. Hu, 2018: An update on the estimate of predictability of seasonal mean atmospheric variability using North American Multi-Model Ensemble. Climate Dyn., https://doi.org/10.1007/s00382-016-3217-1, in press.

Kirtman, B. P., and Coauthors, 2014: The North American Multimode Ensemble: Phase-1 seasonal-to-interannual prediction; phase-2 toward developing intraseasonal prediction. Bull. Amer. Meteor. Soc., 95, 585-601, https://doi.org/10.1175/BAMS-D-12-00050.1.

Kumar, A., and M. P. Hoerling, 1995: Prospects and limitations of seasonal atmospheric GCM predictions. Bull. Amer. Meteor. Soc., 76, 335-345, https://doi.org/10.1175/1520-0477(1995)076<0335: PALOSA $>2.0 . \mathrm{CO} ; 2$

_- , and M. Hoerling, 1997: Interpretation and implications of observed inter-El Niño variability. J. Climate, 10, 83-91, https://doi.org/10.1175/1520-0442(1997)010<0083: IAIOTO $>2.0 . \mathrm{CO} ; 2$.

$\longrightarrow$, and - 1998: Annual cycle of Pacific-North American seasonal predictability associated with different phase of ENSO. J. Climate, 11, 3295-3308, https://doi.org/10.1175/ 1520-0442(1998)011<3295:ACOPNA > 2.0.CO;2.

— , and R. Murtugudde, 2013: Predictability, uncertainty and decision making: A unified perspective to build a bridge from weather to climate. Curr. Opin. Environ. Sustainability, 5, 327-333, https://doi.org/10.1016/j.cosust.2013.05.009.

— , and H. Wang, 2015: On the potential of extratropical SST anomalies for improving climate predictions. Climate Dyn., 44, 2557-2569, https://doi.org/10.1007/s00382-014-2398-8.

, and M. Chen, 2015: Inherent predictability, requirements on the ensemble size, and complementarity. Mon. Wea. Rev., 143, 3192-3203, https://doi.org/10.1175/MWR-D-15-0022.1.

_ and - 2017: What is the variability in US west coast winter precipitation during strong El Niño events? Climate Dyn., 49 , 2789-2802, https://doi.org/10.1007/s00382-016-3485-9.

— A. A. Barnston, P. Peng, M. P. Hoerling, and L. Goddard, 2000: Changes in the spread of the variability of the seasonal mean atmospheric states associated with ENSO. J. Climate, 13, 3139-3151, https://doi.org/10.1175/15200442(2000)013<3139:CITSOT > 2.0.CO;2.

— B. Jha, Q. Zhang, and L. Bounoua, 2007: A new methodology for estimating the unpredictable component of seasonal at mospheric variability. J. Climate, 20, 3888-3901, https://doi. org/10.1175/JCLI4216.1.

, - _ and M. L'Heureux, 2010: Are tropical SST trends changing the global teleconnection during La Niña? Geophys. Res. Lett., 37, L12702, https://doi.org/10.1029/2010GL043394. 
—, M. Chen, L. Zhang, W. Wang, Y. Xue, C. Wen, L. Marx, and B. Huang, 2012: An analysis of the nonstarionarity in the bias of sea surface temperature forecasts for the NCEP Climate Forecast System (CFS) version 2. Mon. Wea. Rev., 140, 30033016, https://doi.org/10.1175/MWR-D-11-00335.1.

,-- , M. P. Hoerling, and J. Eischeid, 2013: Do extreme climate events require extreme forcings. Geophys. Res. Lett., 40, 3440-3445, https://doi.org/10.1002/grl.50657.

Lau, N.-C., 1997: Interaction between global SST anomalies and midlatitude atmospheric circulation. Bull. Amer. Meteor. Soc., 78, 21-24, https://doi.org/10.1175/1520-0477(1997)078<0021: IBGSAA $>2.0 . \mathrm{CO} ; 2$.

Livezey, R. E., M. Masutani, A. Leetmaa, H. Rui, M. Ji, and A. Kumar, 1997: Teleconnective response of the Pacific-North American region atmosphere to large central equatorial $\mathrm{Pa}-$ cific SST anomalies. J. Climate, 10, 1787-1820, https://doi.org/ 10.1175/1520-0442(1997)010<1787:TROTPN > 2.0.CO;2.

Madden, R. A., 1976: Estimates of the natural variability of timeaveraged sea-level pressure. Mon. Wea. Rev., 104, 942-952, https:// doi.org/10.1175/1520-0493(1976)104<0942:EOTNVO>2.0.CO;2.

National Research Council, 2010: Assessment of Intra-Seasonal to Inter-Annual Climate Prediction and Predictability. National Academics Press, 199 pp.

Paek, H., J.-Y. Yu, and C. Qian, 2017: Why were the 2015/2016 and 1997/1998 extreme El Niños different? Geophys. Res. Lett., 44, 1848-1856, https://doi.org/10.1002/2016GL071515.

Peng, P., and A. Kumar, 2005: A large ensemble analysis of the influence of tropical SSTs on seasonal atmospheric variability. J. Climate, 18, 1068-1085, https://doi.org/10.1175/JCLI-3314.1.

- _ - and W. Wang, 2011: An analysis of seasonal predictability in coupled model forecasts. Climate Dyn., 36, 637648, https://doi.org/10.1007/s00382-009-0711-8.

_ - A. G. Barnston, and A. Kumar, 2013: A comparison of skill between two versions of the NCEP Climate Forecast System (CFS) and CPC's operational short-lead seasonal outlooks. Wea. Forecasting, 28, 445-462, https://doi.org/ 10.1175/WAF-D-12-00057.1.

Quan, X., M. Hoerling, L. Smith, J. Perlwitz, T. Zhang, A. Hoell, K. Wolter, and J. Eischeid, 2018: Extreme California rains during winter 2015/16: A change in El Niño teleconnection? Bull. Amer. Meteor. Soc., 99 (Suppl)., https://doi.org/10.1175/ BAMS-D-17-0118.1.

Reynolds, R. W., T. M. Smith, C. Liu, D. B. Chelton, K. S. Casey, and M. G. Schlax, 2007: Daily high-resolution-blended analyses for sea surface temperature. J. Climate, 20, 5473-5496, https://doi.org/10.1175/2007JCLI1824.1.

Robinson, W., 2000: Review of WETS-The Workshop on Extra-Tropical SST anomalies. Bull. Amer. Meteor. Soc., 81, 567-577, https://doi.org/10.1175/1520-0477(2000)081<0567: ROWTWO $>2.3 . \mathrm{CO} ; 2$

Ropelewski, C. F., and M. S. Halpert, 1986: North America precipitation and temperature associated with the El Niño/Southern Oscillation (ENSO). Mon. Wea. Rev., 114,
2352-2362, https://doi.org/10.1175/1520-0493(1986)114<2352: NAPATP $>2.0 . \mathrm{CO} ; 2$.

_ , and —-, 1987: Global and regional scale precipitation patterns associated with the El Niño/Southern Oscillation. Mon. Wea. Rev., 115, 1606-1626, https://doi.org/10.1175/ 1520-0493(1987)115<1606:GARSPP>2.0.CO;2.

$\longrightarrow$, and 1989: Precipitation patterns associated with the high index phase of the Southern Oscillation. J. Climate, 2, 268-284, https://doi.org/10.1175/1520-0442(1989)002<0268: PPAWTH $>2.0 . \mathrm{CO} ; 2$.

Saha, S., and Coauthors, 2010: The NCEP Climate Forecast System Reanalysis. Bull. Amer. Meteor. Soc., 91, 1015-1057, https:// doi.org/10.1175/2010BAMS3001.1.

and Coauthors, 2014: The NCEP Climate Forecast System version 2. J. Climate, 27, 2185-2208, https://doi.org/10.1175/ JCLI-D-12-00823.1.

Seager, R., M. Hoerling, S. Schubert, H. Wang, B. Lyon, A. Kumar, J. Nakamura, and N. Henderson, 2015: Causes of the 2011-14 California drought. J. Climate, 28, 6997-7024, https://doi.org/ 10.1175/JCLI-D-14-00860.1.

Shukla, J., and M. Wallace, 1983: Numerical simulation of the atmospheric response to equatorial Pacific sea surface temperature anomalies. J. Atmos. Sci., 40, 1613-1630, https://doi.org/ 10.1175/1520-0469(1983)040<1613:NSOTAR > 2.0.CO;2.

Siler, N, Y. Kosaka, S.-P. Xie, and X. Li, 2017: Tropical ocean contributions to California's surprisingly dry El Niño of 2015/16. J. Climate, 30, $10067-10079$, https://doi.org/ 10.1175/JCLI-D-17-0177.1.

Tippett, M. K., R. Kleeman, and Y. Tang, 2004: Measuring the potential utility of seasonal climate prediction. Geophys. Res. Lett., 31, L22201, https://doi.org/10.1029/2004GL021575.

Trenberth, K. E., G. W. Branstrator, D. Karoly, A. Kumar, N.- C. Lau, and C. Ropelewski, 1998: Progress during TOGA in understanding and modeling global teleconnections associated with tropical sea surface temperatures. J. Geophys. Res., 103, 14 291-14 324, https://doi.org/ 10.1029/97JC01444.

Wang, W., and A. Kumar, 1998: A GCM assessment of atmospheric seasonal predictability associated with soil moisture anomalies over North America. J. Geophys. Res., 103, 28 63728 646, https://doi.org/10.1029/1998JD200010.

Weisheimer, A., N. Schaller, C. O'Reilly, D. A. MacLeod, and T. N. Palmer, 2017: Atmospheric seasonal forecasts of the twentieth century: Multi-decadal variability in predictive skill of the winter North Atlantic Oscillation (NAO) and their potential for extreme event attribution. Quart. J. Roy. Meteor. Soc., 143, 917-926, https://doi.org/10.1002/ qj.2976.

Xue, Y., M. Chen, A. Kumar, Z.-Z. Hu, and W. Wang, 2013: Prediction skill and bias of tropical Pacific seas surface temperature in the NCEP Climate Forecast System version 2. J. Climate, 26, 5358-5378, https://doi.org/10.1175/ JCLI-D-12-00600.1. 